\title{
Improvement of the Corrosion Resistance of Carbon Steel by Plasma Deposited Thin Films
}

\author{
Rita C.C. Rangel, Tagliani C. Pompeu, José Luiz S. Barros Jr., \\ César A. Antonio, Nazir M. Santos, Bianca O. Pelici, \\ Célia M.A. Freire, Nilson C. Cruz and Elidiane C. Rangel \\ Paulista State University, \\ University of Campinas, \\ Brazil
}

\section{Introduction}

It is estimated that nearly $3 \%$ of the global domestic gross product, corresponding to 2.8 trillion US dollars, is wasted every year with problems related to corrosion (Koch et al., 2002). Oil and gas companies, for instance, spend up to US\$ 80 billion only with the corrosion of devices in marine environments (Muntasser et al., 2002). About $90 \%$ of the corrosion costs are associated with iron-based materials. Since carbon steels, which account for about $85 \%$ of the annual worldwide steel production, represent the largest class of ironalloys in use, the corrosion of such materials is of paramount importance. Notwithstanding many years of intensive research and development, there is not available an ideal protection method. A convenient method to protect metals is by the use of physical barriers against species such as water, oxygen and hydrogen. In this context, organic coatings have been considered as the most effective protective barriers. In particular, epoxy-based resins are widely applied to protect carbon steel due to easiness of processing and excellent mechanical and chemical resistances (Shin et al., 2010). However, in extended exposures to environment such rigid coatings can fail and once a defect occurs, the corrosive species can reach the metal surface resulting in localized corrosion. Owing to that, frequently the protection with epoxy demands pretreatments or the incorporation of corrosion inhibitors (Radhakrishnan et al., 2009), which may incur in prohibitive extra costs.

A potentially useful method to produce organic coatings with adjustable composition and thickness, on virtually any kind of substrate is the technique known as Plasma Enhanced Chemical Vapor Deposition (PECVD) (Biederman et al., 1992, Yasuda, 1985). Since the characteristics of the films grown by PECVD are strongly influenced by the deposition conditions, it is possible to tailor the properties of the coatings to best fulfill the requirements of a given application. In this work it is discussed the effectiveness of plasma deposited films on the improvement of carbon steel corrosion resistance. The discussions are based on results obtained from a-C:H:Si films deposited onto SAE 1012 samples by glow 
discharge radiofrequency plasmas generated in atmospheres of oxygen and hexamethyldisiloxane (HMDSO) vapor. With varying the plasma excitation power, the corrosion resistance, determined by electrochemical impedance spectroscopy, increased up to 5 orders of magnitude if compared to the pristine material. Interpretations are provided based on the film thickness, density and roughness.

\section{Experimental details}

The depositions of the films were performed using the system illustrated in Fig.1. It consists of a cylindrical glass chamber of 7 liters in volume, with two parallel stainless steel electrodes. The lower electrode was used as sample holder while a metallic mesh was used as the upper electrode to facilitate the gas feeding to the inter-electrode region.

Prior to the depositions the samples were cleaned in ultrasonic baths using detergent solution, distillated water and isopropyl alcohol and then the substrates were dried with a hot air gun. Subsequently, they were sputter-cleaned during $600 \mathrm{~s}$. To carry out this process, the chamber was evacuated down to $1 \mathrm{~Pa}$ and hydrogen and argon were admitted in the reactor in equal proportion. The total pressure of the gases was $1 \mathrm{~Pa}$ and the plasmas were generated by application of radiofrequency power, RF, $(13.56 \mathrm{MHz}, 150 \mathrm{~W})$ to the sample holder while the upper electrode was grounded. After the plasma cleaning, the depositions were performed during $3600 \mathrm{~s}$ in atmosphere of $\mathrm{HMDSO}$ and $\mathrm{O}_{2}$, in equal proportions, by RF application to the sample holder. The total pressure was kept at $20 \mathrm{~Pa}$ and the RF power was varied from 50 to $250 \mathrm{~W}$. Figure 2 shows a picture taken from the system during the deposition process.

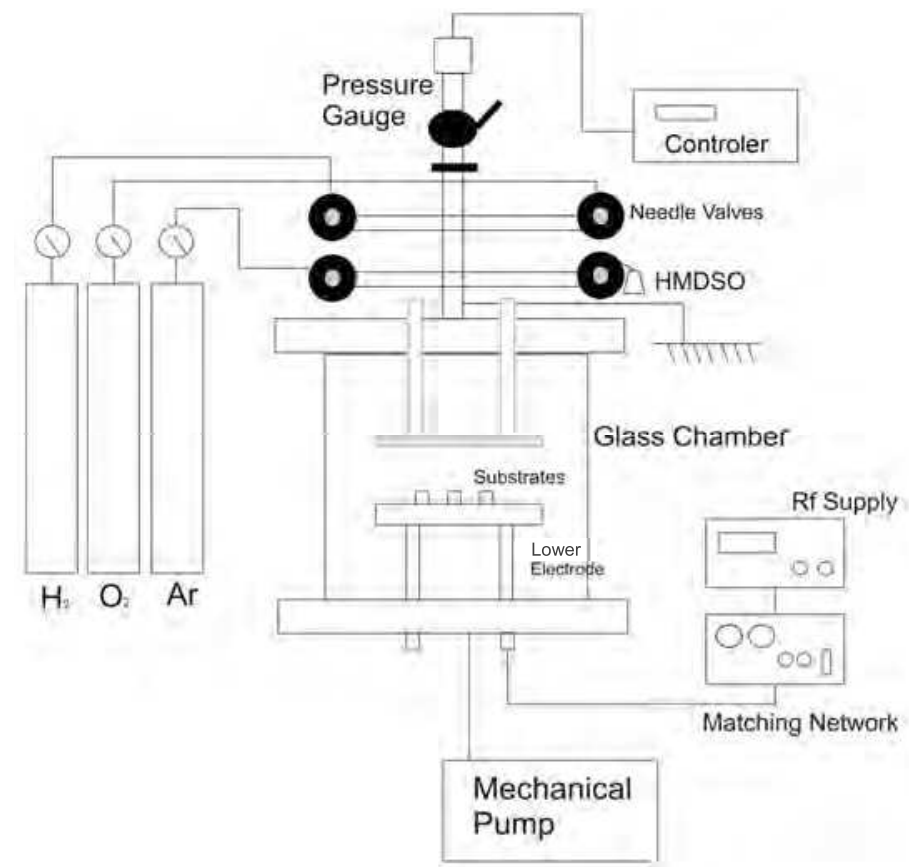

Fig. 1. Experimental apparatus employed in film deposition. 


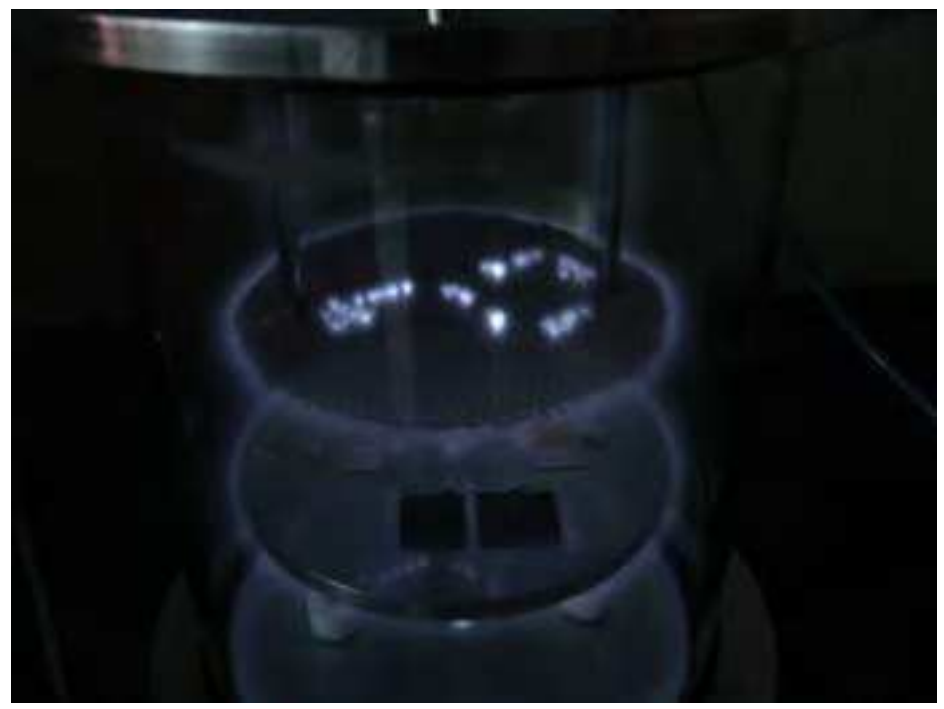

Fig. 2. Picture of the system during the deposition process.

The molecular structure of the films deposited onto polished stainless steel was analyzed by infrared reflectance-absorbance spectroscopy in a JASCO FTIR 410 spectrometer. Spectra were collected with 124 measurements with a resolution of $4 \mathrm{~cm}^{-1}$. The morphology of the carbon steel surface was analyzed by scanning electron microscopy in a Zeiss, EVO MA-15 system. The acceleration voltage was $-20 \mathrm{kV}$ and the micrographs were acquired with the secondary electrons detector. The effect of the film deposition on the topography of the carbon steel was investigated by atomic force microscopy in contact mode in a Hysitron Triboindenter. The setpoint was $4.0 \mu \mathrm{N}$ and RMS roughness was evaluated from the complete image area $\left(50 \times 50 \mu \mathrm{m}^{2}\right)$. Surface wettability was assessed from contact angle, $\theta$, measurements using an automated goniometer Ramé-Hart 100. Three drops of deionized water were deposited on different positions of carbon steel plates coated with the plasma deposited film. The results correspond to the average of ten measurements performed with each drop. Film thickness was measured with a profilometer (Veeco, Dektak 150) from a step made onto a glass slide during the deposition, using Kapton adhesive tape as a mask. The deposition rate was calculated by dividing the thickness by deposition time. This instrument also enabled the evaluation of surface roughness of the plasma coated carbon steel plates. All the experiments related to perfilometry were conducted in, at least, three different positions of each sample. Electrochemical impedance spectroscopy (EIS) experiments were performed using a lock-in amplifier (EG\&G Instrument, 5210) coupled to a Potentiostat-Galvanostat System (EG\&G PAR, 273A), connected to a three-electrode electrochemical cell. Either pristine carbon steel or carbon steel coated with the films was used as the working electrode. A platinum foil was used as counter-electrode and a saturated calomel electrode was used as reference electrode. EIS measurements were obtained at open-circuit potential with the samples in a $0.05 \mathrm{M}-\mathrm{NaCl}$ solution with frequency ranging from $10^{5}$ to $10^{-2} \mathrm{~Hz}$, with amplitude of $10 \mathrm{mV}$. The immersion time ranged from 0 to $10800 \mathrm{~s}$. The oxidation resistance of the surfaces was also evaluated from the etching rate, in oxygen or sulfur hexafluoride plasmas. In both cases, samples prepared 
onto glass plates were exposed for $1800 \mathrm{~s}$ to plasmas generated with excitation power of 50 $\mathrm{W}$ and at 1.3 Pa. For each sample, the thickness of the plasma generated step was probed in three different positions. To avoid interferences, for all the investigations conducted here, one exclusive sample was prepared for each different test.

Deviations in the results may occur mainly due to the lack of chemical and physical homogeneity of the employed carbon steel. Such variations are observed to strongly affect the surface properties of a solid providing heterogeneous data. Furthermore, the dependence of the plasma treatment results on the geometrical factors, specifically in this case, the sample radial distance from the center of the electrode, is another relevant aspect that may generate deviations. However, to avoid this problem the samples prepared for each analysis were always placed exactly at the same position with respect to the center of the electrode. Moreover, as all the technical recommendations were strictly observed during the plasma treatments, the results that will be presented here are reproducible, according to previous observations.

\section{Results and discussions}

The thickness, $h$, and the deposition rate, $R$, of the films are presented in Fig. 3 as a function of the plasma excitation power, $\mathrm{P}$. There is progressive rise in $\mathrm{h}$ with increasing $\mathrm{P}$ up to 200 $\mathrm{W}$ and a sudden fall afterwards, associated to film delamination. Since the deposition time was maintained constant $(3.600 \mathrm{~s})$ in all the experiments, $\mathrm{R}$ follows the same trend, reaching its maximum value $(\sim 300 \mathrm{~nm} / \mathrm{min})$ at $200 \mathrm{~W}$. In order to understand such results some plasma phenomena should be considered. First of all, the effect of the excitation power on the mean electron energy and density. The density of electrons with energies high enough to activate plasma species rises with P (Choudhury et al., 2010) if other plasma parameters are kept unchanged. As electrons are the energy carriers in such environments, the probability of bond fragmentation, excitation and ionization through inelastic collisions grows. Plasma activity increases intensifying all the processes taking place as deposition, ablation and ion bombardment.

Ion bombardment during the deposition has important implications for the final properties of the system. As in this work substrates were placed at the driven electrode, under the action of the self bias polarization, positive ions are accelerated through the sheath and implanted in the exposed surfaces. It is well known that self bias voltage scales with the excitation power (Choudhury, et al., 2011) if the gas pressure is kept constant. Thus, the increment in P leads to an increment in the ion accelerating potential which has two effects: it increases the flux of low energy carbon ions towards the substrate surface, affecting the deposition velocity (Morosoff, 1990), and also provides more energy to the newly formed layer what is decisive for the final material properties. Therefore, the slope in the curves of Fig.3 can be attributed to changes in the deposition kinetics due to variations in the intensity of the ion bombardment and in the density/energy of the electrons in the plasma and it is expect that such alterations would change not only deposition rate but also the film characteristics.

The infrared spectra of the films are shown in Fig.4. The wavenumber of the absorptions and their respective assignments are listed in Table 1 . The main vibrational modes of the monomer molecule (HMDSO) are identified revealing the incorporation of the organosilicon fragments in the film structure. 


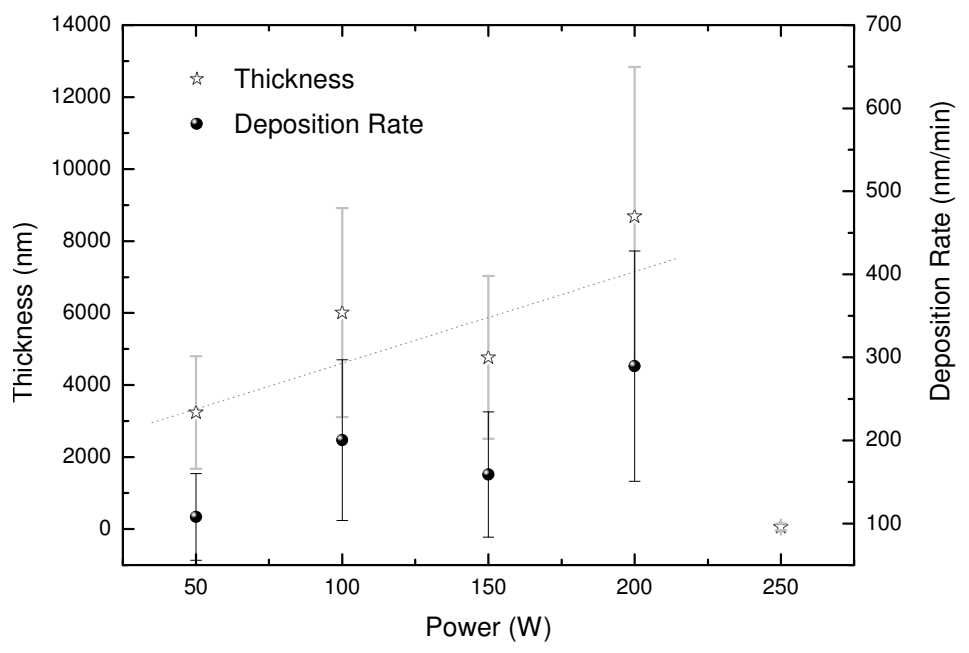

Fig. 3. Thickness and deposition rate of the films as a function of the plasma excitation power.

In the spectrum of the film deposited with the lowest power, $50 \mathrm{~W}$, there are contributions related to C-H stretching $\left(2839,2902\right.$ and $\left.2961 \mathrm{~cm}^{-1}\right)$ and bending $(1257,1354,1411$ and 1440 $\mathrm{cm}^{-1}$ ) modes. The presence of adsorbed water and carbonyl groups is suggested by the contributions around 1600 and $1727 \mathrm{~cm}^{-1}$, respectively. The retention of silicon in the film is evidenced by absorptions centered at 1020 ( $v$ Si-O) and $1130\left(v\right.$ Si-O) $\mathrm{cm}^{-1}$. In the low wavenumber region, other contributions also ascribed to silicon-containing groups, appear around $700\left(\delta \mathrm{Si}-\mathrm{H}_{\mathrm{n}}\right), 755\left(v \mathrm{C}-\mathrm{H}\right.$ in $\left.\mathrm{Si}\left(\mathrm{CH}_{3}\right)_{3}\right), 782(v \mathrm{Si}-\mathrm{C}), 806\left(v \mathrm{Si}-\mathrm{O}, \nu \mathrm{Si}-\mathrm{C}\right.$ and $\left.\delta \mathrm{CH}_{3}\right), 836$ $(v \mathrm{Si}-\mathrm{C})$ and $851\left(\delta \mathrm{CH}_{3} \mathrm{Si}\left(\mathrm{CH}_{3}\right)_{3}\right) \mathrm{cm}^{-1}$.

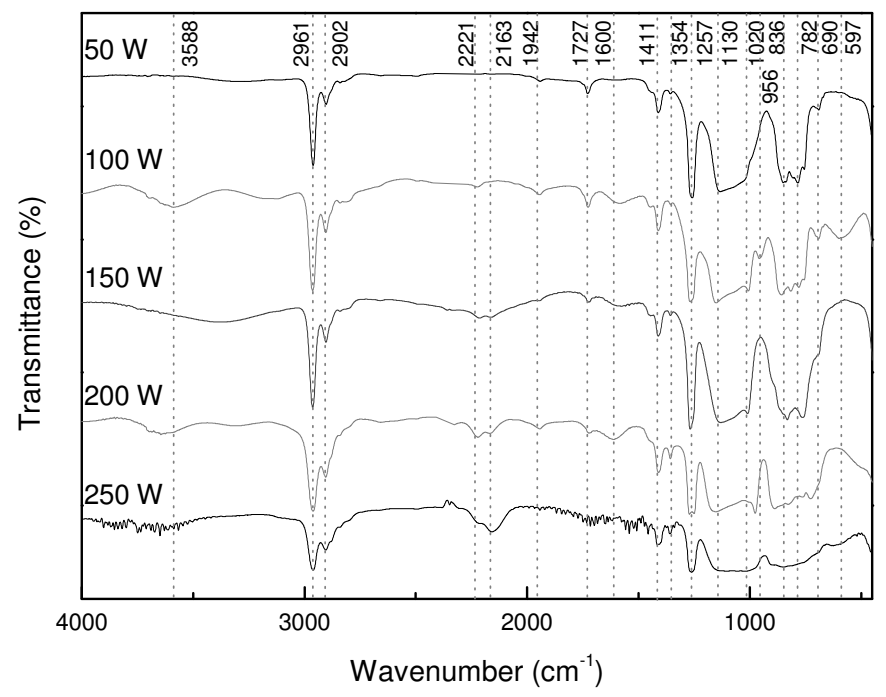

Fig. 4. Infrared spectra of films deposited in plasmas of different powers. 
All the above mentioned absorptions are evident in the spectra, but modifications are detected with increasing P. In the spectrum of the sample prepared with $100 \mathrm{~W}$, there is emergence of bands laying around 3588 and $956 \mathrm{~cm}^{-1}$, respectively related to the stretching and bending modes of $\mathrm{O}-\mathrm{H}$ vibrations in silanol groups. Once $\mathrm{O}-\mathrm{H}$ is not originally present in the structure of the organic molecule, the observation of this group indicates multiple step reactions in the plasma phase. In the spectra of the films prepared with 150 and $200 \mathrm{~W}$, these vibrations are no longer detected, but they retain large bands centered at $3370(150 \mathrm{~W})$ and $3636 \mathrm{~cm}^{-1}(200 \mathrm{~W})$. While the first is characteristic of intermolecular hydrogen bonded O-H, the second is ascribed to O-H in primary alcohols $\left(\mathrm{R}-\mathrm{CH}_{2}-\mathrm{OH}\right)$ (Scheinmann, 1970), reveling alteration in the hydroxyl form of incorporation. The depletion of silanol groups can also be associated to an increment in the crosslinking degree (Fracassi et al., 2003).

\begin{tabular}{|c|c|c|c|}
\hline Wavenumber $\left(\mathrm{cm}^{-1}\right)$ & Assignments & Groups & \\
\hline 690,700 & $\mathrm{Si}-\mathrm{H}_{\mathrm{n}}$ & & (Guruvenket et al., 2010) \\
\hline $\begin{array}{l}755 \\
782\end{array}$ & $\begin{array}{l}\delta \mathrm{C}-\mathrm{H}_{3} \\
v \mathrm{Si}-\mathrm{C}\end{array}$ & $\begin{array}{l}\mathrm{Si}-\left(\mathrm{CH}_{3}\right)_{3} \\
\mathrm{Si}-\left(\mathrm{CH}_{3}\right)_{2}\end{array}$ & $\begin{array}{c}\text { (Rao et al., 2010) } \\
\text { (Guruvenket et al., 2010) }\end{array}$ \\
\hline 806 & $\begin{array}{c}v \mathrm{Si}-\mathrm{O} \\
v \mathrm{Si}-\mathrm{C}, \delta \mathrm{CH}_{3}\end{array}$ & $\begin{array}{l}\mathrm{Si}-\mathrm{O}-\mathrm{Si} \\
\mathrm{Si}\left(\mathrm{CH}_{3}\right)_{x}\end{array}$ & $\begin{array}{c}\text { (Choudhury et al., 2010) } \\
\text { (Gengenbach et al., 1999, } \\
\text { Scheinmann, 1970) }\end{array}$ \\
\hline $\begin{array}{l}836 \\
851\end{array}$ & $\begin{array}{l}\vee \mathrm{Si}-\mathrm{C} \\
\delta \mathrm{C}-\mathrm{H}_{3}\end{array}$ & $\begin{array}{l}\mathrm{Si}-\left(\mathrm{CH}_{3}\right)_{x} \\
\mathrm{Si}-\left(\mathrm{CH}_{3}\right)_{3}\end{array}$ & $\begin{array}{c}\text { (Rao et al. 2010) } \\
\text { (Gengenbach et al., 1999) }\end{array}$ \\
\hline 956 & $\delta \mathrm{O}-\mathrm{H}$ & $\mathrm{Si}-\mathrm{OH}$ & $\begin{array}{c}\text { ((Ricci et al, 2011, } \\
\text { Choudhury et al., 2010) }\end{array}$ \\
\hline 1020,1130 & $v \mathrm{Si}-\mathrm{O}$ & $\mathrm{Si}-\mathrm{O}-\mathrm{Si}$ & $\begin{array}{c}\text { (Gengenbach et al., 1999, } \\
\text { Fracassi et al., 2003) }\end{array}$ \\
\hline 1257 & $\delta \mathrm{C}-\mathrm{H}_{3}$ & $\mathrm{Si}-\left(\mathrm{CH}_{3}\right)_{x}$ & $\begin{array}{c}\text { (Gengenbach et al., 1999, } \\
\text { Choudhury et al., 2010) }\end{array}$ \\
\hline 1354 & $\delta \mathrm{C}-\mathrm{H}_{2}$ & $\mathrm{Si}-\mathrm{CH}_{2}-\mathrm{Si}$ & (Ul et al., 2000) \\
\hline 1411,1440 & $\delta \mathrm{C}-\mathrm{H}$ & $\mathrm{Si}-\left(\mathrm{CH}_{3}\right)_{x}$ & $\begin{array}{c}\text { (Rao et al., 2010, Ul et al., } \\
\text { 2000) }\end{array}$ \\
\hline 1600 & $\mathrm{O}-\mathrm{H}$ & Free Water & (Rao et al., 2010) \\
\hline 1727 & $v \mathrm{C}=\mathrm{O}$ & $\mathrm{CH}_{2} \mathrm{O}$ & (Ricci et al., 2011) \\
\hline 2163,2221 & $v \mathrm{Si}-\mathrm{H}$ & & (Ul et al, 2000) \\
\hline 2902 & $v \mathrm{C}-\mathrm{H}$ & $\mathrm{CH}_{2}$ & (Gengenbach et al., 1999) \\
\hline 2961,2839 & $v \mathrm{C}-\mathrm{H}$ & $\mathrm{CH}_{3}$ and $\mathrm{CH}_{2}$ & $\begin{array}{c}\text { (Gengenbach et al., 1999, } \\
\text { Scheinmann, 1970) }\end{array}$ \\
\hline 3588 & $v \mathrm{O}-\mathrm{H}$ & $\mathrm{Si}-\mathrm{OH}$ & $\begin{array}{c}\text { (Ricci et al., 2011, } \\
\text { Choudhury et al., 2010) }\end{array}$ \\
\hline
\end{tabular}

Table 1. Assignments of the bands in the infrared spectra of the films and their related groups. Symbols $v$ and $\delta$ represent stretch and deformation vibrations, respectively.

Still in the spectrum of the film deposited with $100 \mathrm{~W}$, there appears bands at 2163 and 2221 $\mathrm{cm}^{-1}$, ascribed to $\mathrm{Si}-\mathrm{H}$ stretching in good agreement with the presence of the band related to Si-H bending mode $\left(\sim 700 \mathrm{~cm}^{-1}\right)$. The intensity of all Si-H contributions increases with $\mathrm{P}$, indicating progressive growth of the dissociation and recombination processes in the plasma phase. Figure 5 presents the trends in the relative density of $\mathrm{Si}-\mathrm{H}$ bonds as a function of $\mathrm{P}$, 
evaluated from the model proposed by (Lanford and Rand, 1978). In fact the Si-H proportion tends to increase with $\mathrm{P}$, but the growing rate was observed to be higher for the films deposited with 150 and $250 \mathrm{~W}$.

The absorption related to Si-O vibrations, at $1020 \mathrm{~cm}^{-1}$, shifts to lower wavenumbers with increasing $\mathrm{P}$ indicating film densification what is also consistent with higher proportions of Si-H groups (Rao et al., 2010) in the structure. This effect is clearly evidenced in Fig.6 which highlights the bands in the low wavenumber region. On the other hand, the intensification of this contribution (up to $200 \mathrm{~W}$ ) reflects the increment of Si-O-Si fraction and therefore, of the crosslinking degree (Gengenbach et al., 1999). Thus, both changes observed in the band around $1020 \mathrm{~cm}^{-1}$ are consistent with a silicon enrichment with increasing $\mathrm{P}$. The noticeable widening and loss of resolution of all the bands arising in the low wave number region (< $1000 \mathrm{~cm}^{-1}$ ) suggest changes (disorder) in the neighborhood of the chemical bond due to a higher diversification of fragments incorporated in the structure.

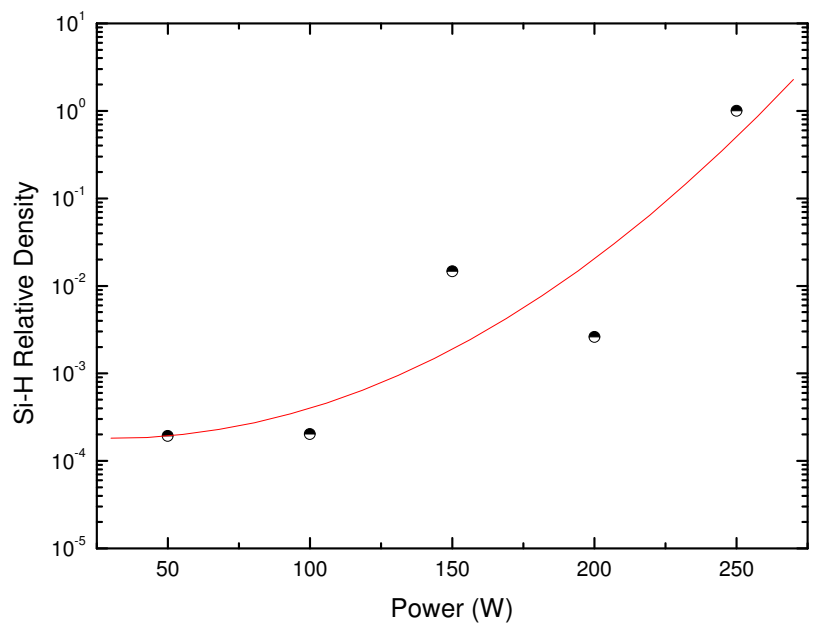

Fig. 5. Relative density of Si-H bands in the film as a function of the plasma excitation power.

An evolution is also observed in the bands related to $\mathrm{C}-\mathrm{H}$ deformation in $\mathrm{CH}_{3}\left(1411 \mathrm{~cm}^{-1}\right)$ and $\mathrm{CH}_{2}\left(1354 \mathrm{~cm}^{-1}\right)$ groups. Whereas the first keeps roughly unchanged, the second increases with $\mathrm{P}$. The growth of the bands related to $\mathrm{CH}_{2}$ species is an evidence that fragmentation of $\mathrm{Si}\left(\mathrm{CH}_{3}\right)_{3}$ groups is an important route of the polymerization process, differently of the results found in the work of Gengenbach (Gengenbach et al., 1999). Indeed, such a mechanism represents one of the major fragmentation process in HMDSO plasma processes. The overall intensity of the band around $1260 \mathrm{~cm}^{-1}\left(\mathrm{CH}_{3}\right.$ in $\left.\mathrm{Si}\left(\mathrm{CH}_{3}\right)_{\mathrm{x}}\right)$ is also changed in the spectra of Fig.6: it is observed to decrease with P despite the increment of the film thickness. This result indicates continuous depletion of $\mathrm{Si}\left(\mathrm{CH}_{3}\right)_{x}$ groups, probably by methyl or hydrogen abstraction, generating dangling bonds were $\mathrm{Si}-\mathrm{H}$ groups can be formed. According to Rao (Rao, 2010), the reduction in the intensity of this band is associated to the increase in the structure crosslinking. 
Even though thickness results indicated complete film detachmentfrom the sample prepared at $250 \mathrm{~W}$, infrared spectrum detected the presence of the layer. After careful visual inspections it was observed that film detached of some substrates and was preserved in others. The aging time upon atmospheric conditions also influenced the adhesion of this sample to the substrates.

Figure 7 shows the contact angle, $\theta$, of the films as a function of the plasma excitation power. All the surfaces are hydrophobic presenting contact angles higher than $90^{\circ}$. The film which presented the lowest $\theta$ value was the prepared with $100 \mathrm{~W}$. It is interesting to point out that this was the only sample in which silanol groups were detected in the infrared spectra (956 and $3588 \mathrm{~cm}^{-1}$ ). The presence of such species is normally associated to points where hydrolization can occur upon exposition to atmosphere or to water solutions, providing an early deterioration of the barrier properties. For $\mathrm{P}>100 \mathrm{~W}$, there is no significant variation of $\theta$ which keeps around $104^{\circ}$.

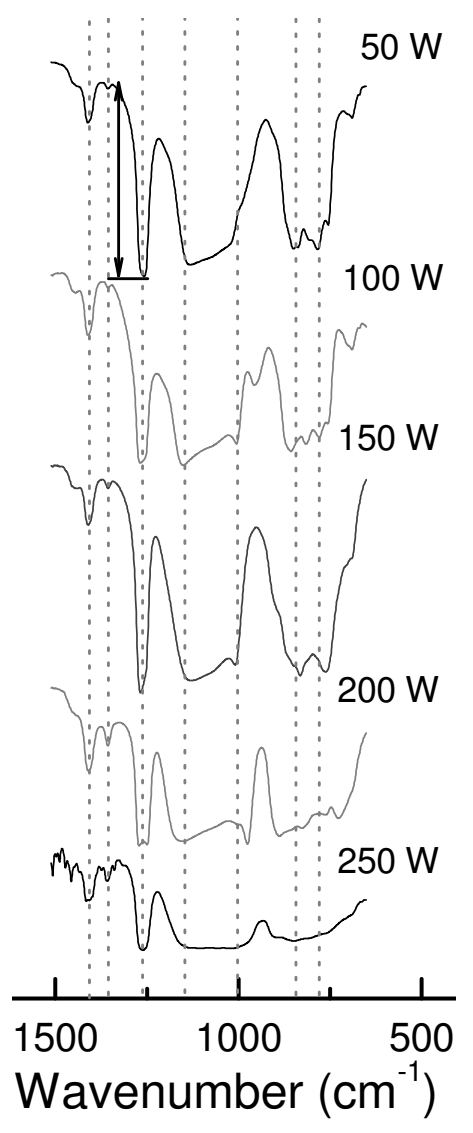

Fig. 6. Infrared spectra of the films prepared in plasmas of different power in the low wavenumber region. 


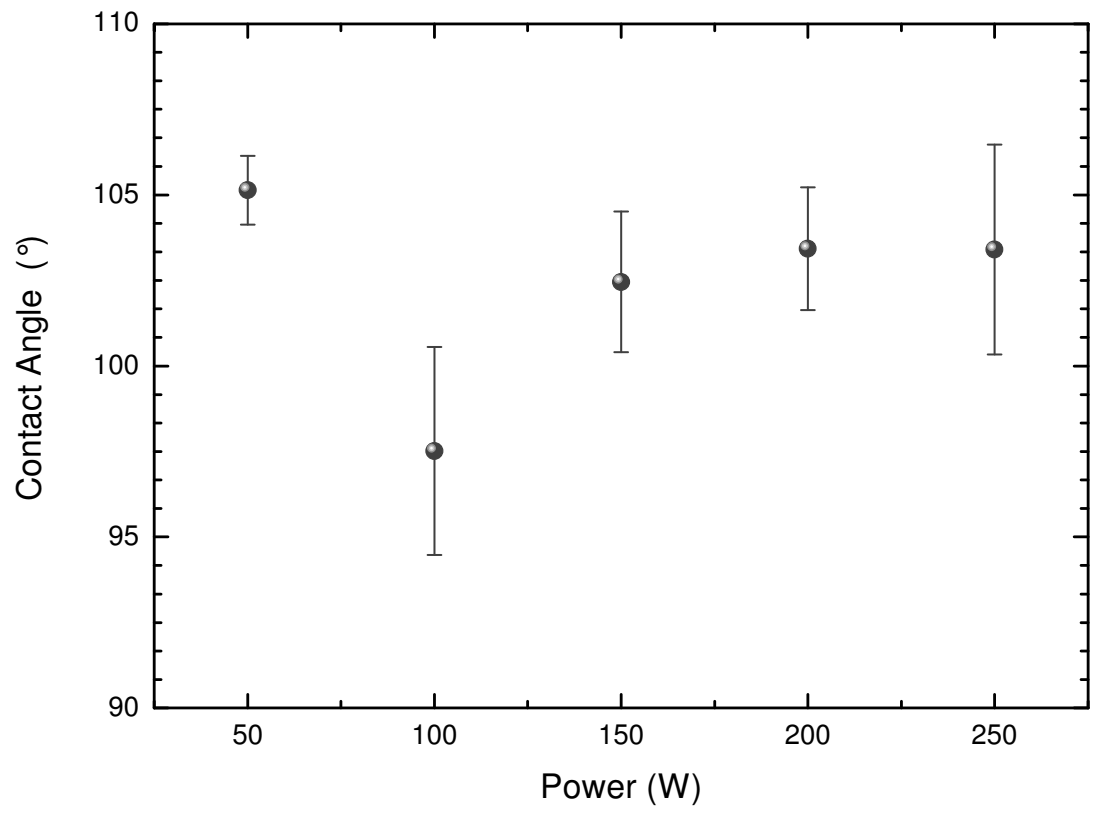

Fig. 7. Contact angle of the films as a function of the plasma excitation power.

It is interesting to observe the extreme difference in the water wettability as one consider silicon oxide and plasma deposited HMDSO films. In the first, the high concentration of polar Si-O groups attains high surface energy to the material, stimulating the incorporation of $\mathrm{O}-\mathrm{H}$ atmospheric groups. These groups favor the connection of atmospheric water molecules through hydrogen bonds, affecting the way water spreads onto the surface. Even though films prepared from HMDSO plasmas normally present high proportions of Si-O groups, they are shielded by the non polar methyl groups, reducing the electrostatic force over water molecules. Therefore, as high the proportion of trimethylsylil in the surface, higher the contact angle, what is in good accordance with the results of Fig.7: the film prepared with the lowest power associated the highest $\mathrm{Si}\left(\mathrm{CH}_{3}\right)_{\times}$proportion to the highest $\theta$ value.

Another important aspect as one considers water wettability is surface topography. Changes in roughness alter the contact area of the droplet varying the intensity of the electrostatic forces. Figure 8 shows the roughness of the as-received (dotted line) and plasma deposited carbon steel as a function of P. In a general way, film deposition reduces the substrate roughness for any deposition condition employed here. Furthermore, the roughness upshifts just for the samples prepared at 150 and $250 \mathrm{~W}$ of power. 


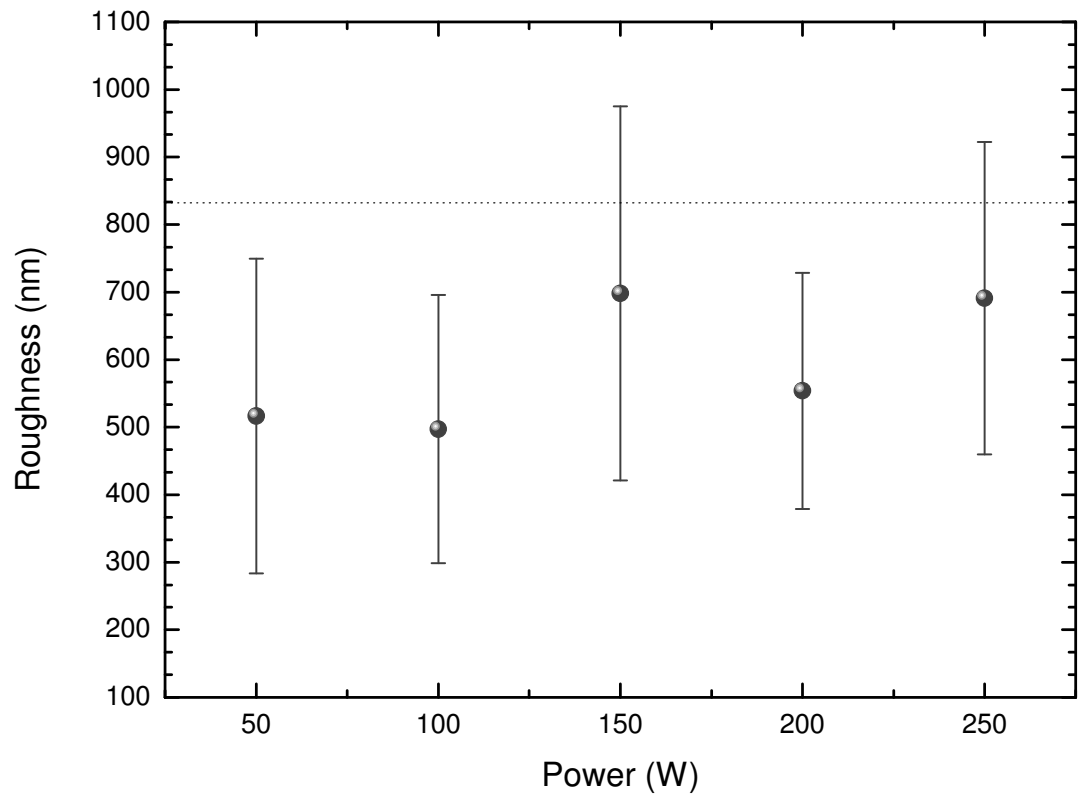

Fig. 8. Roughness of the films as a function of the plasma excitation power. Dotted line represents the roughness of the bare carbon steel.

To evaluate the effect of the roughness on the water wettability, the graph of Fig.9 was built. It is well accepted in the literature that for hydrophobic materials the increment in surface roughness intensifies the repulsive electrostatic forces due to the increase in the contact area (Quéré, 2005). However, films prepared here are hydrophobic by the absence of electrostatic forces and not by intense repulsive interactions. Therefore, it is expected that roughness increment could expose Si-O polar groups by structural rearrangements, increasing their electrostatic interactions with polar water molecules. In this case, roughness increment would tend to reduce $\theta$. Through the results presented in Fig.9, it is indeed observed a slight fall tendency in $\theta$ with increasing roughness above $500 \mathrm{~nm}$, suggesting interference of the relief on the contact angle. But the topographical changes do not explain the steep $\theta$ slope for the first two points in the graph, since roughness is practically constant for them $(497 \pm$ 198 and $516 \pm 233 \mathrm{~nm})$. In fact, the lowest $\theta$ value presented by the smoothest sample (100 $\mathrm{W})$ coincides with the appearance of silanol groups in the structure. Therefore, plasma power affects wettability of the films due to the chemical and topographical alterations, being the first one the most prominent in the definition of the trends. 


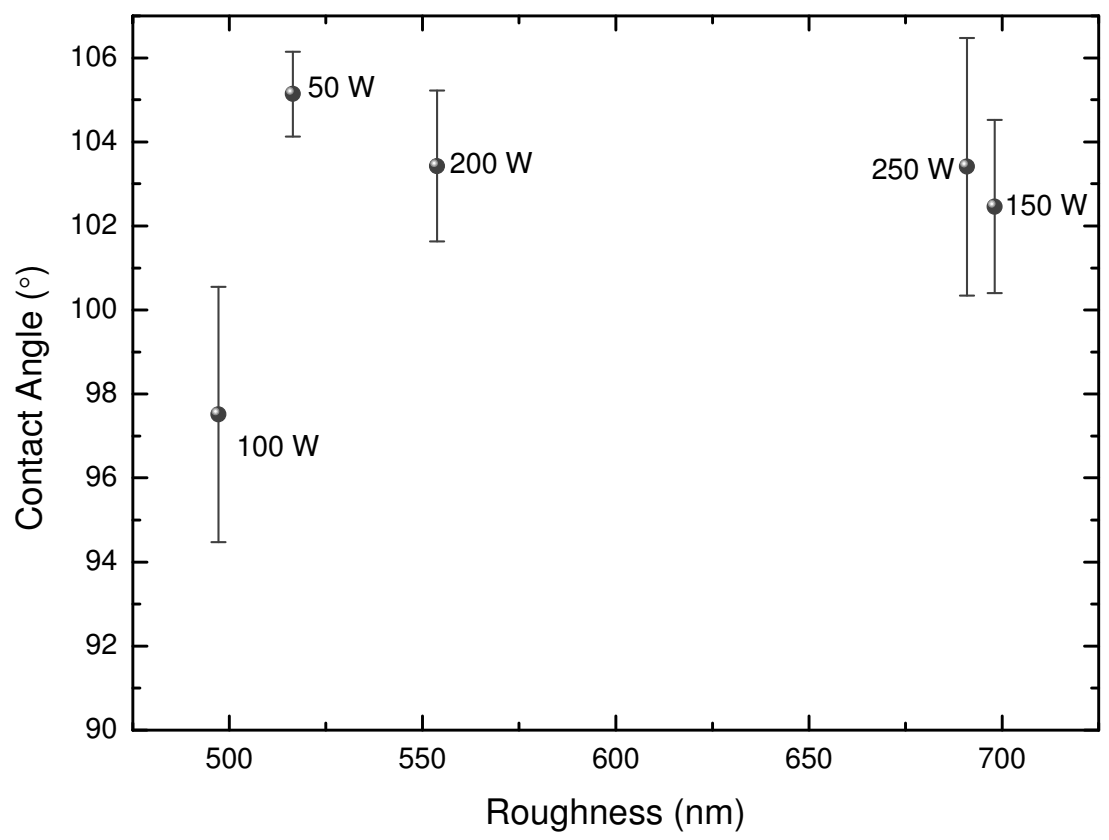

Fig. 9. Contact angle as a function of the roughness of the films.

The corrosion of Si-containing films upon fluorine- and oxygen-rich environments is a matter of interest in microelectronic (Chen et al., 2011, Stillahn et al., 2011) and aerospace (Huang et al., 2011) applications, respectively. To evaluate the chemical response of the films to such media, samples were exposed to reactive plasmas generated from $\mathrm{SF}_{6}$ or $\mathrm{O}_{2}$. The etching rates derived from these experiments are presented in Fig. 10 as a function of the film deposition power. The removal of the layer material in $\mathrm{SF}_{6}$ plasmas is slower for the films prepared with 50 and $100 \mathrm{~W}$ and rises around $30 \%$ with increasing $\mathrm{P}$ to 150 and $200 \mathrm{~W}$. Since the layers prepared with the highest power levels presented progressive loss of $\mathrm{C}-\mathrm{H}$ groups and then silicon enrichment, structures with elevated proportions of $\mathrm{Si}-\mathrm{H}$ and $\mathrm{Si}-\mathrm{O}$ groups were formed. The affinity towards fluorine grows, consistently with the etching rate elevation. This interpretation is supported by the fact that etching rates similar to the reported to silicon wafers in $\mathrm{SF}_{6}$ plasmas ( $90 \mathrm{~nm} / \mathrm{min}$ ) (Tian et al., 2000) were attained to the high power prepared samples. As materials with elevated etching rate and selectivity are desired for designing high aspect ratio microelectrical-mechanical systems, the films prepared with the highest power levels are potential candidates for this area.

It is interesting to note, however, that when the samples were exposed to oxygen plasmas, no material removal was detected by perfilometry indicating the formation of a structure highly resistant to oxygen attack, as required in several aerospace applications. Even though $\mathrm{C}$ is present in huge proportions, it is protected from oxygen attack by formation of a $\mathrm{Si}-\mathrm{O}_{2}$ barrier on the film surface upon oxygen plasma (Bruce et al., 2010). From the moment this protection is created, further material removal is hampered, explaining the undetectable etching rates developed in the films studied here. 


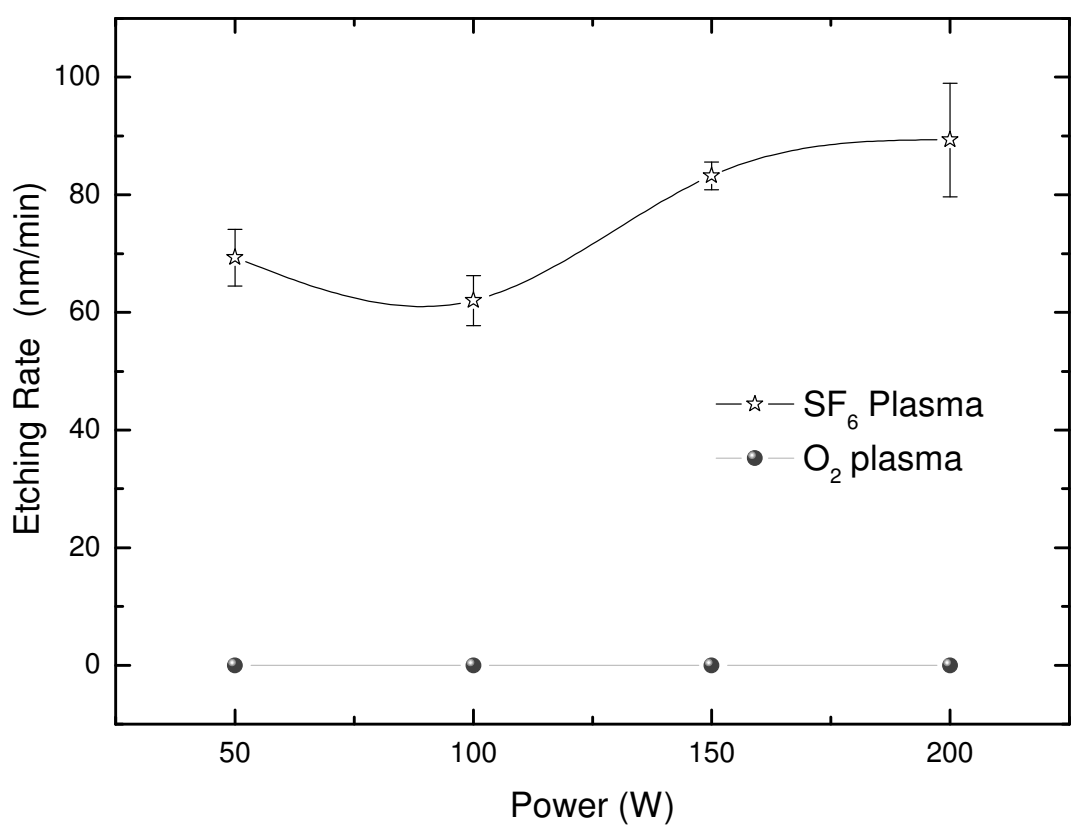

Fig. 10. Etching rate of the films in reactive $\mathrm{SF}_{6}$ and $\mathrm{O}_{2}$ plasmas as a function of the film deposition power.

The resistance of the carbon steel to corrosion in saline solution was evaluated by electrochemical impedance spectroscopy. The results of the phase angle are presented in Fig.11 as a function of frequency, $v$, for the bare and film-containing carbon steel. Measurements were performed varying the immersion time, $t$, from 0 to 180 minutes.

Considering the immersion time $t=0 \mathrm{~min}$, the phase angle of the non-treated substrate increases with frequency reaching a maximum around $10^{1} \mathrm{~Hz}$ and falling afterwards. This one concavity shape reflects the changes in the phase angle provoked by substrateelectrolyte interactions. After film deposition, the low frequency maximum is still detected but a more intense component arises in the high frequency region, affecting the overall shape of the curves. The second maximum is caused by electrolyte- film interactions and the presence of the two components suggests simultaneous reactions on the film and substrate surfaces. The enhancement in the high frequency component, accompanied by the diminution in the low frequency one, reveal a better performance of the system under the corrosive medium. For the sample prepared with $250 \mathrm{~W}$ no improvement was detected with respect to the bare steel since the film partially detached of the substrate. Comparing the phase angles at $10^{5} \mathrm{~Hz}$ in the different graphs, it is noticed an evolution with increasing P: for the bare substrate it is lower than $10^{\circ}$ and increases continuously, reaching $86^{\circ}$ for the sample prepared in plasma of $200 \mathrm{~W}$. Layers with phase angles close to $90^{\circ}$ present a capacitive-like behavior, and act as good corrosion barriers. For the sample prepared with $150 \mathrm{~W}$, the phase angle at $10^{5} \mathrm{~Hz}$ is high but not stable with increasing $\mathrm{t}$ : a continuous fall is observed, reaching the same plateau detected for the bare substrate. Indeed, the shape of 

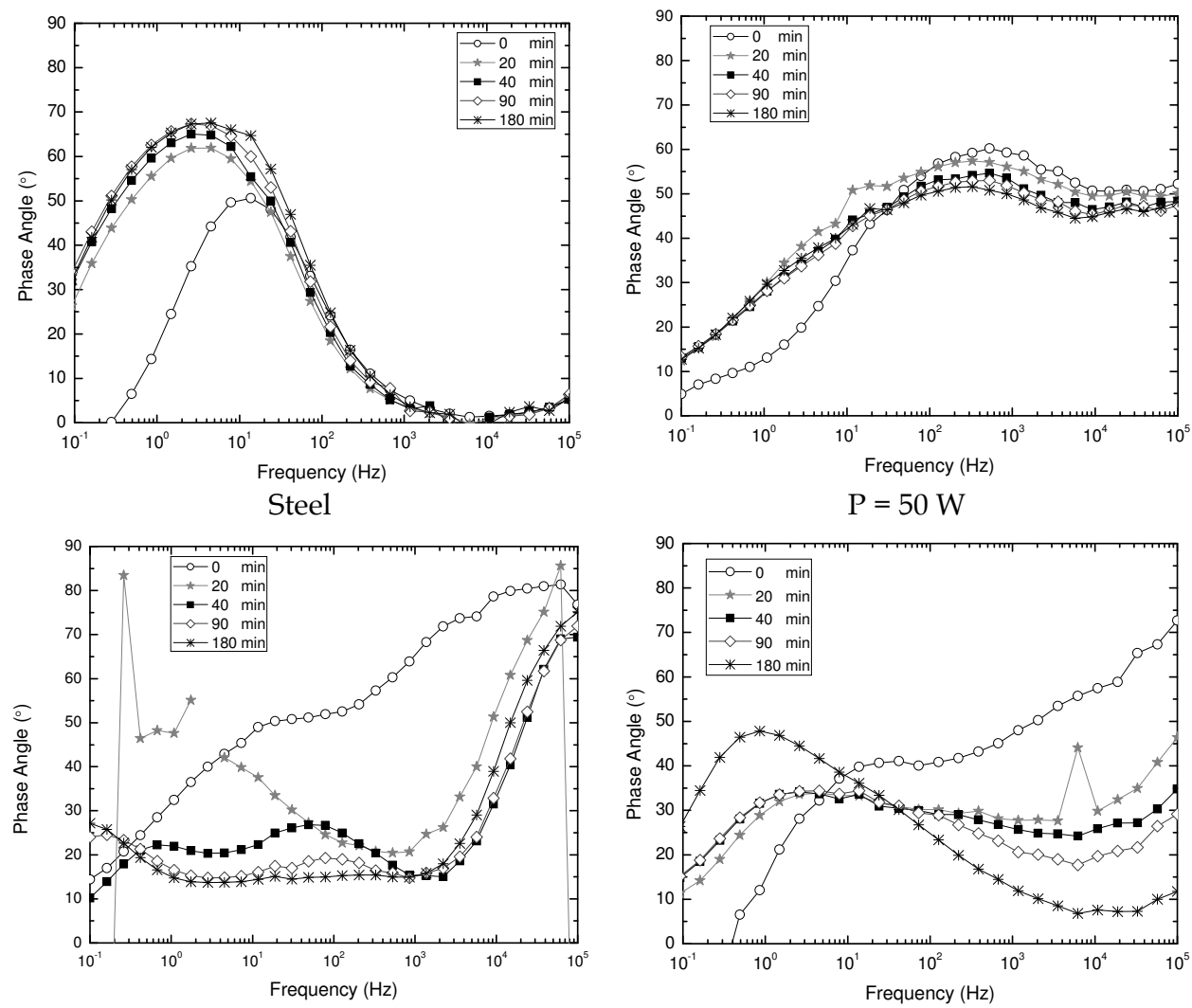

$\mathrm{P}=100 \mathrm{~W}$
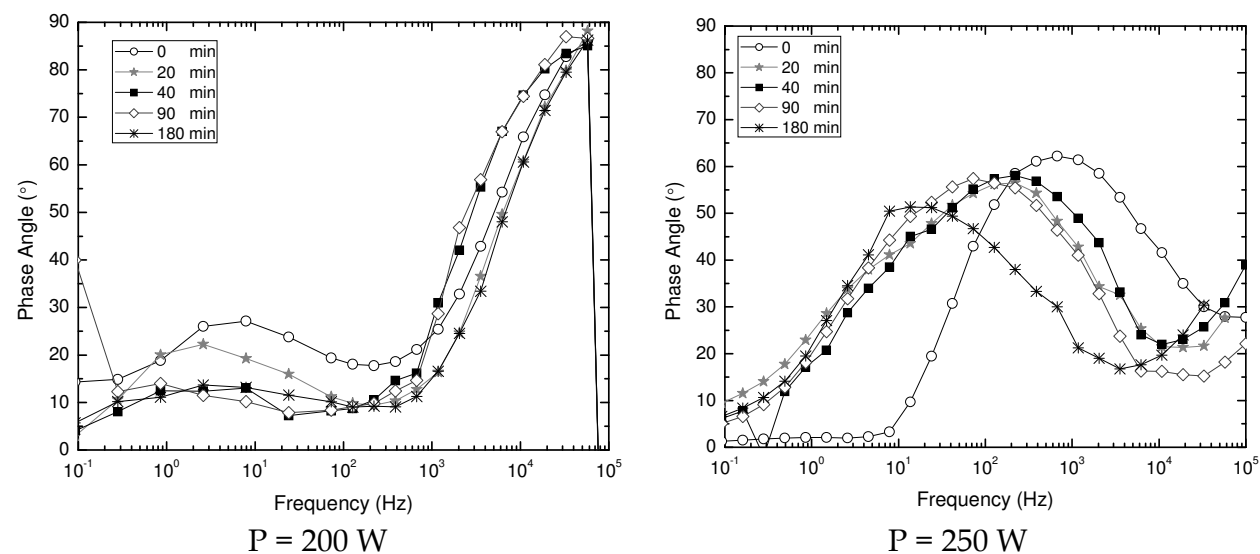

Fig. 11. Phase angle as a function of the frequency taken at different immersion times for the samples prepared on carbon steel in plasmas of different powers. Phase angle for the bare steel substrate is also presented. 
this curve evolutes to that of the bare substrate if the test is conducted for 180 minutes. Although the film deposited with $100 \mathrm{~W}$ presented good results for zero immersion time, they were not preserved with increasing $t$. The treatments which presented the most stable results were those performed with 50 and $200 \mathrm{~W}$, being the last one, the most effective for the corrosion protection of the carbon steel.

Figure 12 shows the impedance modulus as a function of frequency for the bare- and filmcontaining carbon steel. In a general way, $|Z|$ decreases with increasing $v$, achieving the lowest impedance at the high frequency extreme. Independently of the deposition condition employed, film application upshifts the impedance curves, especially in the low frequency region. Considering the different immersion times, the samples exposed to 50 and $200 \mathrm{~W}$ plasmas presented high stability even after the longest test. On the other hand, a downshift is observed on the curves of the samples prepared in plasmas of 100,150 and $250 \mathrm{~W}$, indicating a deterioration of the protective properties upon the corrosion experiments. The lack of a specific trend with $t$ in the curves of the sample deposited at $250 \mathrm{~W}$ may be a consequence of the non uniformity of the remaining layer left onto the substrate.

Using the method proposed in (Mansfeld, 1981), the total resistance $\mathrm{R}_{\mathrm{t}}$, was derived from the impedance modulus curves at the lowest frequency extreme $\left(10^{-1} \mathrm{~Hz}\right)$ and the results are presented in Fig.13 as a function of the immersion time. Comparing the first point of each curve $(\mathrm{t}=0 \mathrm{~min})$ it is readily observed that the film deposited at $250 \mathrm{~W}$ provided no further resistance to the carbon steel. On the other hand, the film prepared with $\mathrm{P}=150 \mathrm{~W}$ enhanced $R_{t}$ by 2 orders of magnitude. Still better results were encountered for the samples exposed to plasmas of 50, 100 and $200 \mathrm{~W}$. In these cases, $R_{t}$ reached $1.5 \times 10^{6}, 2.5 \times 10^{7}$ and $3.1 \times 10^{6} \Omega$, respectively, values substantially higher than the obtained for the bare substrate $\left(5.3 \times 10^{2} \Omega\right)$. Nevertheless, these high impedance values decreased with increasing immersion time to 20 minutes, and kept practically unchanged afterwards. This constancy at elevated values is an important issue as one considers the preservation of the barrier properties under aggressive environments. Under the most aggressive condition employed here $(180 \mathrm{~min}), R_{t}$ was also observed to vary with P: it increases from $1.5 \times 10^{5}$ to $5.4 \times 10^{5} \Omega$ as $\mathrm{P}$ is changed from 50 to $200 \mathrm{~W}$, that is an almost fourfold increase for this P range.

In order to interpret the results of Fig.13 it should be taken into account the effect of the film thickness on the corrosion protection, as depicted in Fig.14. The growth in $\mathrm{R}_{\mathrm{t}}$ scales well with film thickness, except for the sample prepared in $150 \mathrm{~W}$ plasmas. In this case, another factor, besides thickness, seems to have a greater importance for the film performance.

Composition is also a relevant factor for corrosion resistance. In plasma deposited HMDSO films (Ul et al., 2002), the density is observed to increase with the proportion of Si-H bonds due to Si enrichment. From the results presented in Fig. 5, the Si-H proportion augments in the film with increasing P. According to this analysis, the densest layers were prepared in 150 and $250 \mathrm{~W}$ plasmas while the lightest ones were obtained in 50 and $100 \mathrm{~W}$ plasmas. Interestingly, in these extremes $\mathrm{Si}-\mathrm{H}$ contents are separated by four orders of magnitude.

To determine the effect of the silicon content on $R_{t}$, the graph of Fig. 15 was built. Indeed, $R_{t}$ tends to decrease with increasing $\mathrm{Si}-\mathrm{H}$ density, except for the sample prepared at $200 \mathrm{~W}$ which associated intermediary $\mathrm{Si}$ proportions to high thickness values, factor that was determinant for the results found here. 

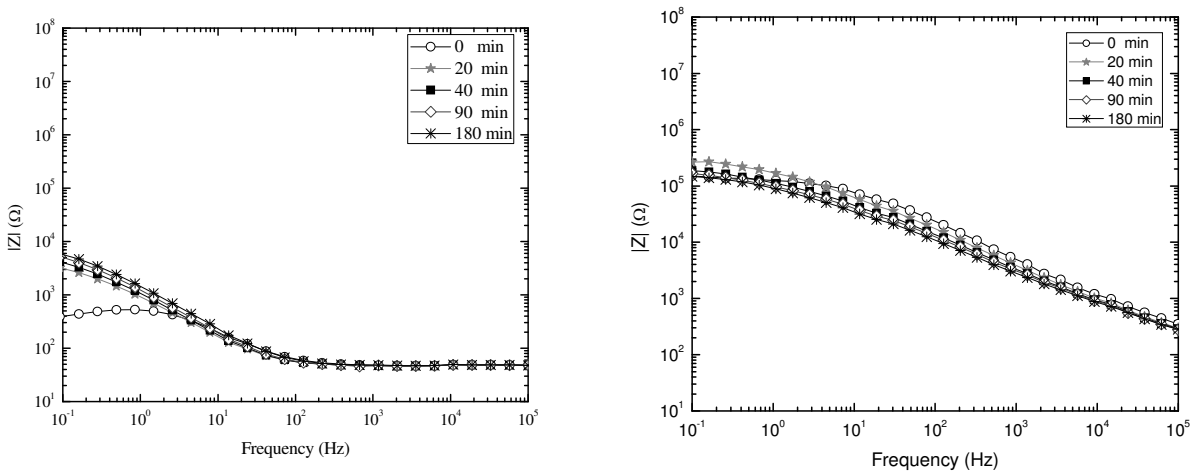

Steel
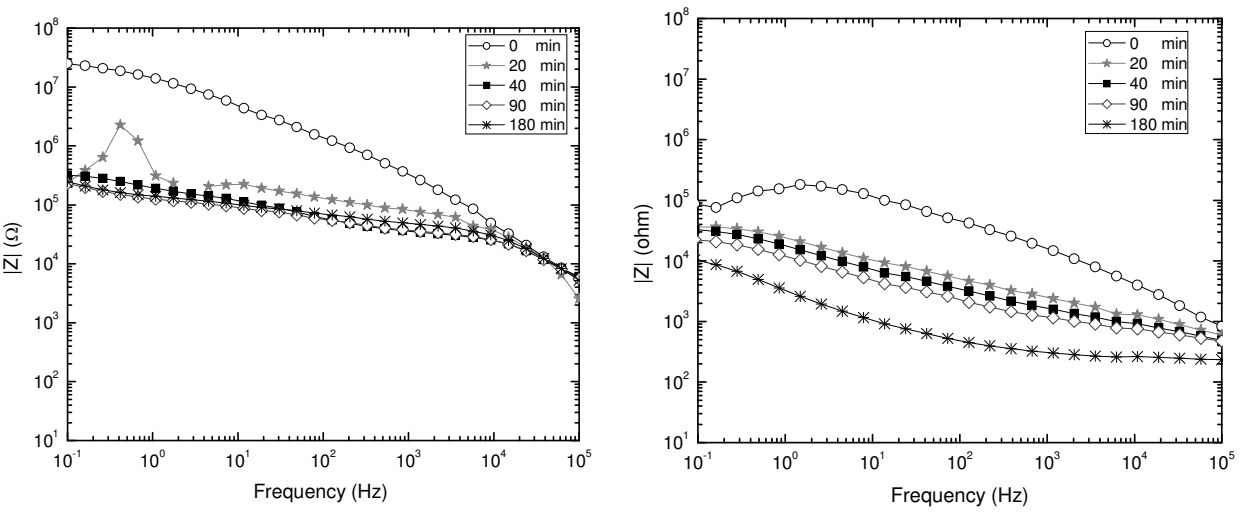

$\mathrm{P}=100 \mathrm{~W}$
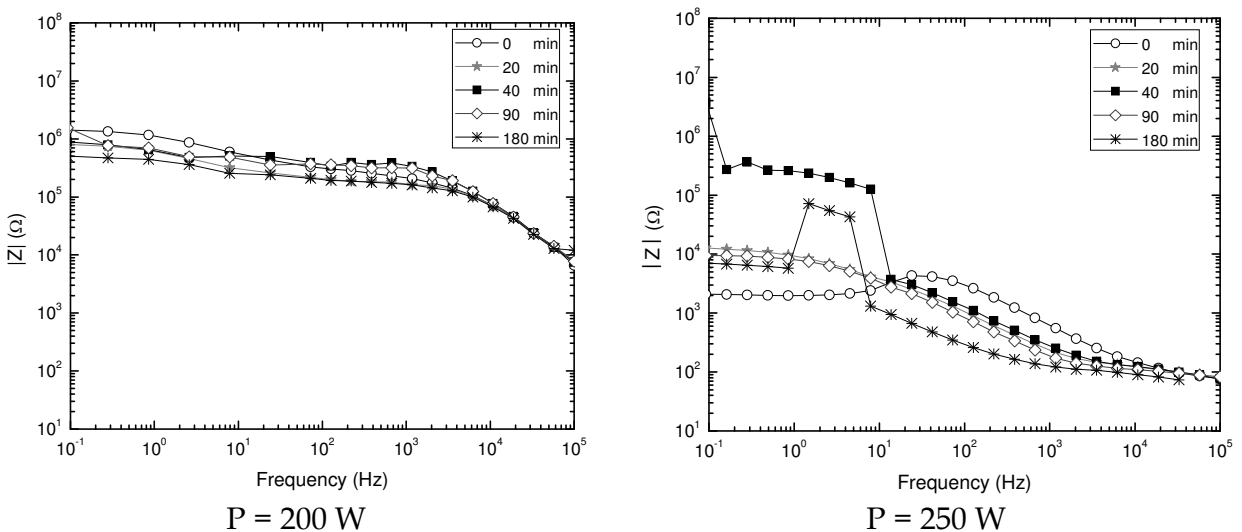

Fig. 12. Impedance modulus as a function of frequency taken at different immersion times for the samples prepared on carbon steel in plasmas excited with different powers. Impedance modulus for the bare steel substrate is also presented. 


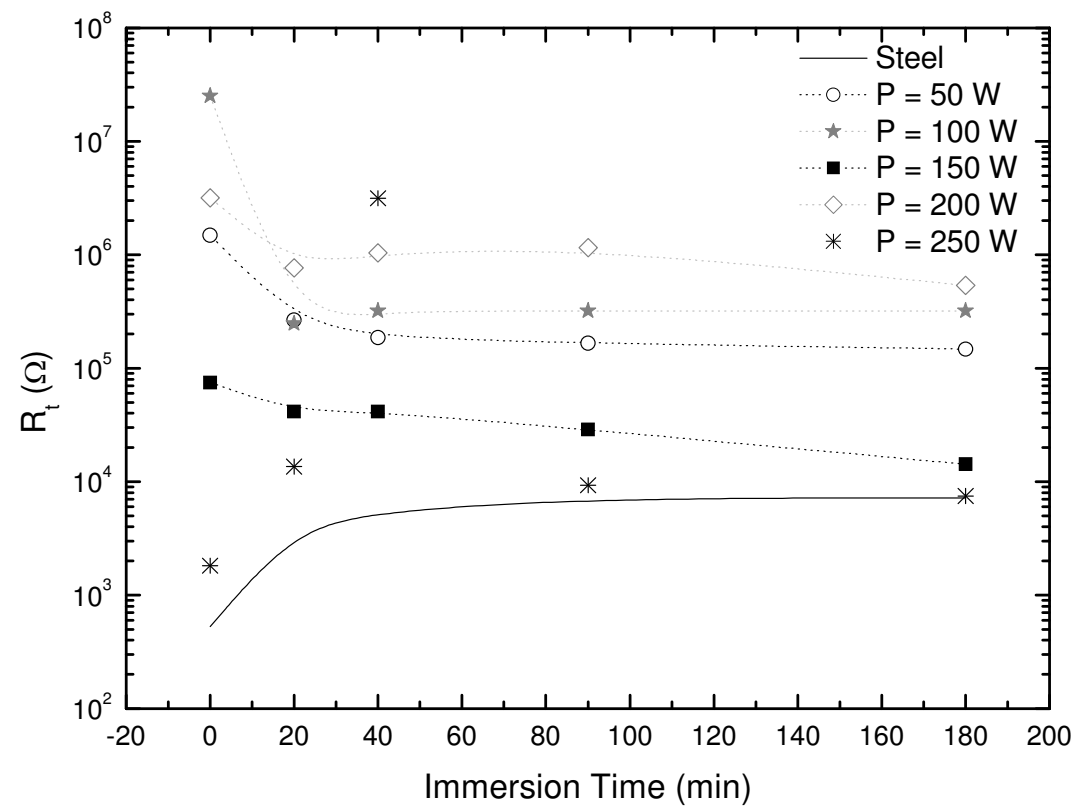

Fig. 13. Total resistance as a function of the immersion time for the samples exposed to plasmas of different powers and for the bare substrate.

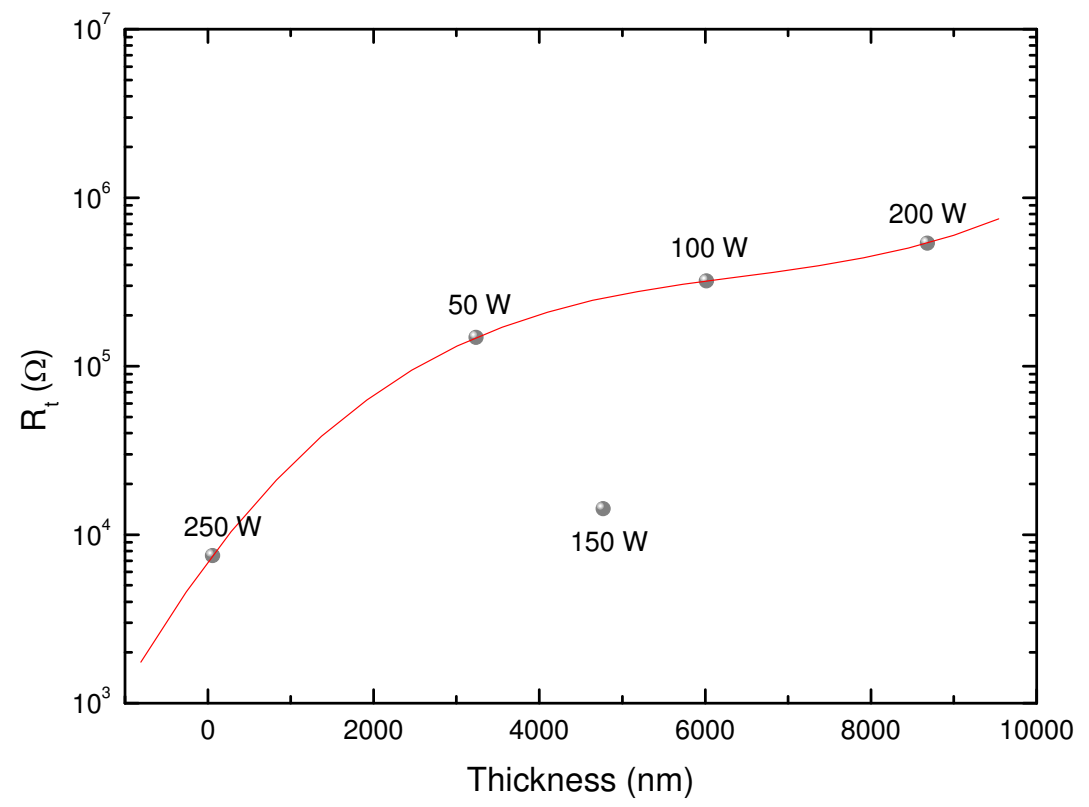

Fig. 14. Total resistance at $\mathrm{t}=180$ minutes as a function of the film thickness. 


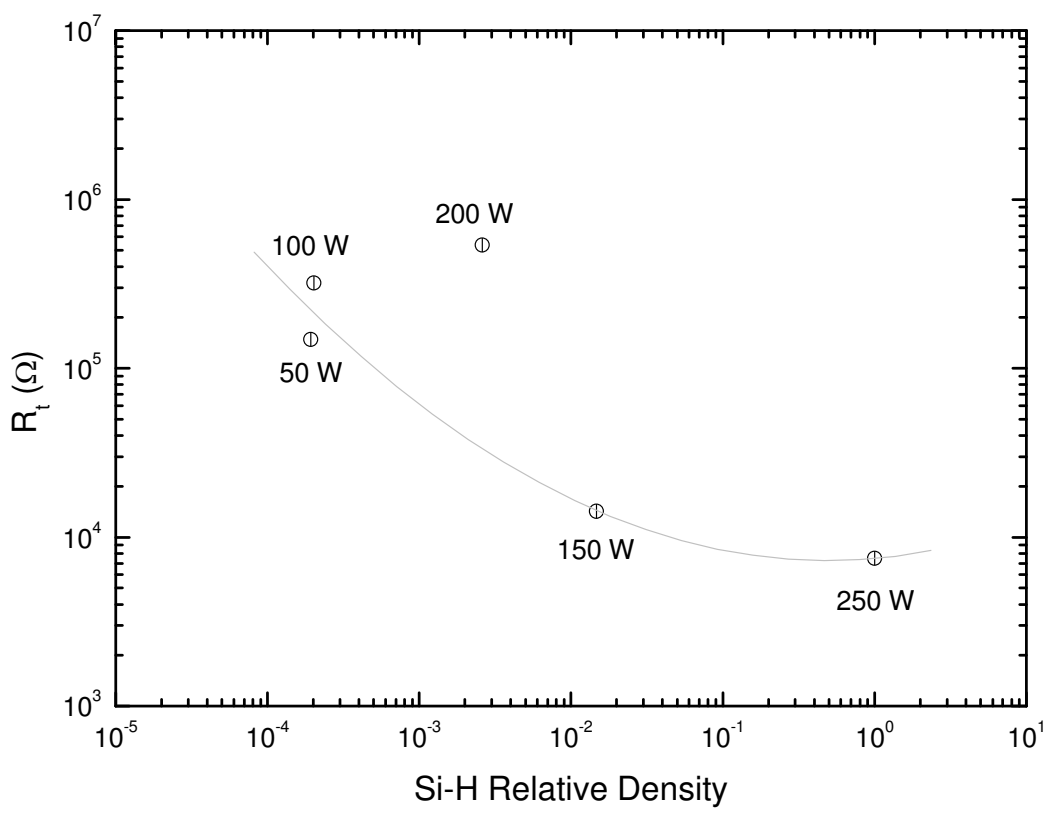

Fig. 15. Total resistance at $\mathrm{t}=180$ minutes as a function of the $\mathrm{Si}-\mathrm{H}$ relative density in the films.

Therefore, the poor corrosion performance of the films prepared with 150 and $250 \mathrm{~W}$ is ascribed to the combination of the low thickness and high Si contents of these samples. Besides, in the layer deposited with $250 \mathrm{~W}$, cracks, pinholes or other kind of defects may originate from the partial film detachment, producing points were the electrolyte can easily diffuse through the layer reaching the substrate. Films deposited with 50 and $100 \mathrm{~W}$ attained low densities of $\mathrm{Si}-\mathrm{H}$ groups and intermediary thicknesses. Finally, the layer which combined high thickness and moderate concentrations of Si-H species $(200 \mathrm{~W})$ presented the highest total resistance and physical stability upon the saline solution.

Scanning electron micrographs of the surfaces, taken prior and after the corrosion experiments, are presented in Fig.16. The bare substrate presents a series of defects throughout the surface, originated of the manufacturing process. After the corrosion tests, such defects are still evident together with residues of the electrolyte-steel reactions. In a general way, film deposition hides the majority of the substrate defects, explaining the roughness fall detected by perfilometry (Fig.8). Just shallow holes and scratches remain on the surfaces indicating incomplete coverage of the deepest imperfections. The structure is formed by the agglomeration of particulates giving rise to a granular film. The dimension of the particulates is observed to increase with P up to $100 \mathrm{~W}$ and to decrease afterwards. However, this dimensional alteration was not observed to influence the roughness results of Fig. 8 . 


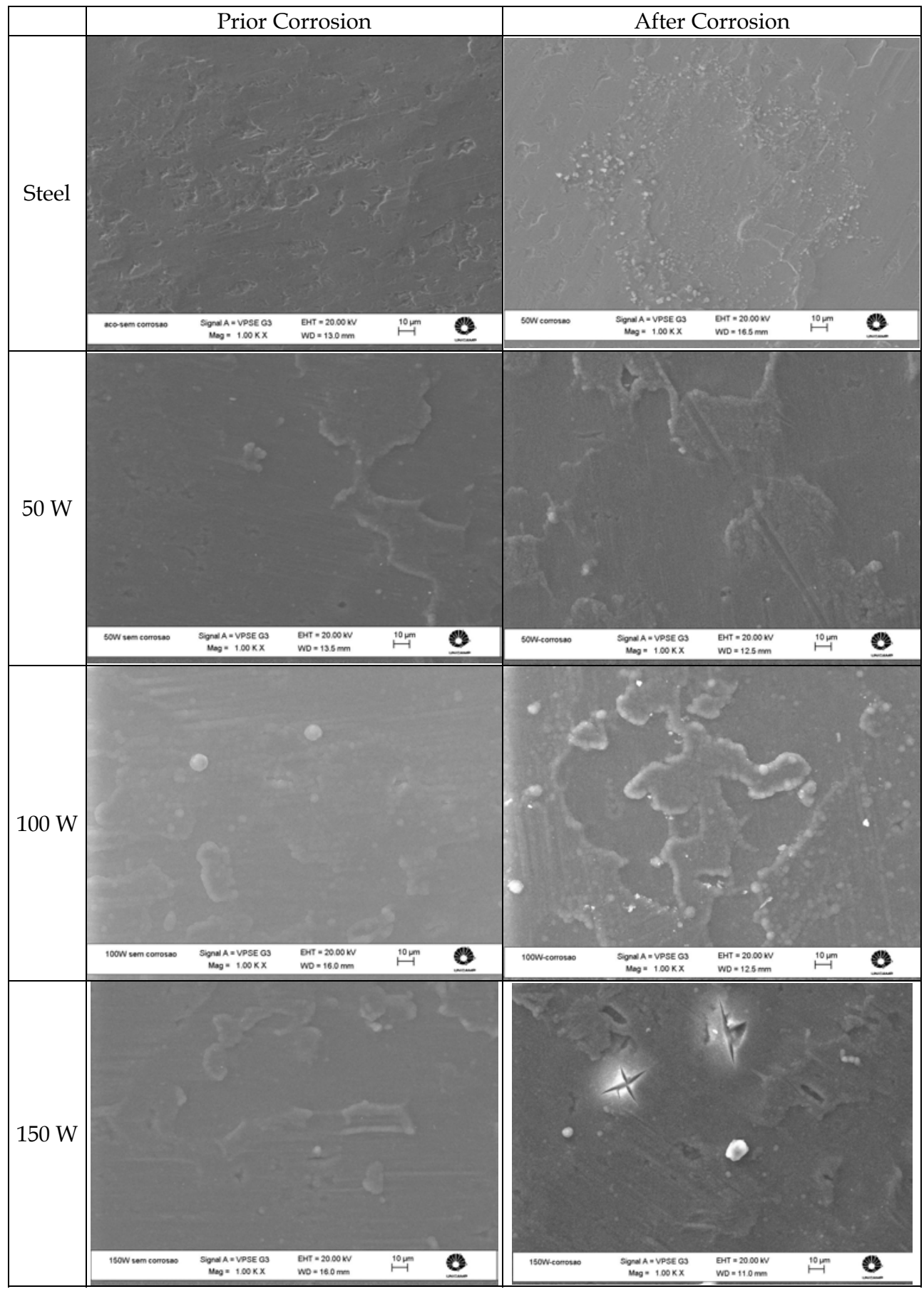




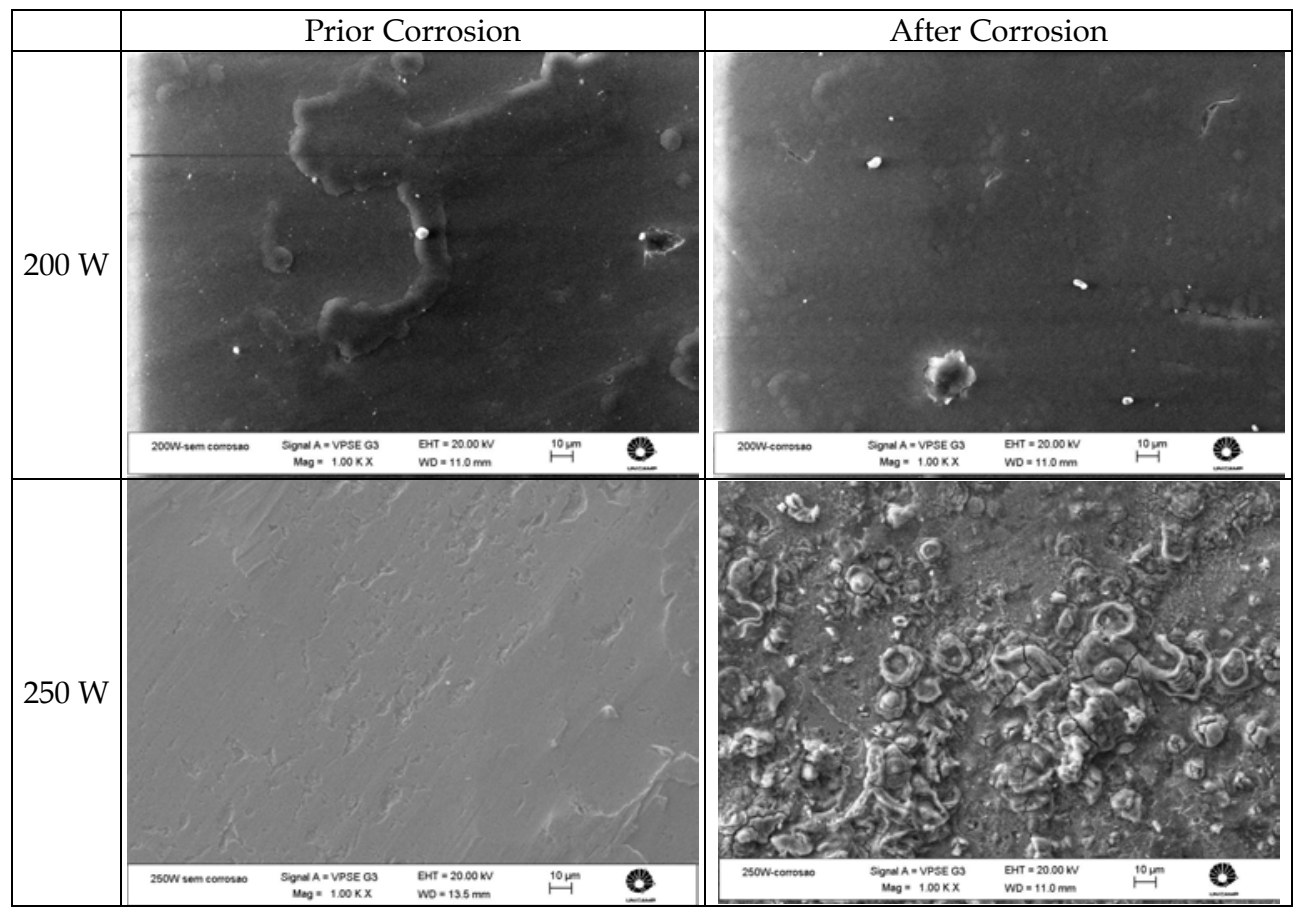

Fig. 16. Micrographs of the samples prepared onto carbon steel in plasmas excited with different powers prior and after corrosion experiments. Micrographs of the bare substrate is also presented for comparison.

Even though structural defects are evident in the films, the overall surface aspect is not changed after the corrosion tests suggesting the presence of the film in their deepest part. Just the sample containing the film deposited with $150 \mathrm{~W}$ presented some star-like cracks that may be responsible for its early fail in the EIS tests. In this case, the high density may generate fragile points in the structure that breaks upon solution absorption. The sample deposited with $250 \mathrm{~W}$ presented the same characteristics of the bare steel, indicating complete film detachment from the analyzed region. This also explains the similar appearance of the EIS curves for the substrate and $250 \mathrm{~W}$ treated sample in Fig.13. For this sample, the post corrosion surface image highlights the film residues and corrosion byproducts precipitated on the surface.

To further evaluate the effect of the power on the relief and morphology of the samples, atomic force microscopy images were acquired and are presented in Fig.17. Line profiles of specific regions are also depicted. Through the information of the image and of the graph line it is possible to verify the kind and dimension of the irregularities in the as-received substrate. After film deposition, cracks, holes and depressions are still detected suggesting that film application was not enough to hide the substrate imperfections. An uniform film containing particles sparsely immersed on it was verified for the sample exposed to $50 \mathrm{~W}$ plasmas. The morphology is strongly altered with increasing power to 100 and $150 \mathrm{~W}$. 


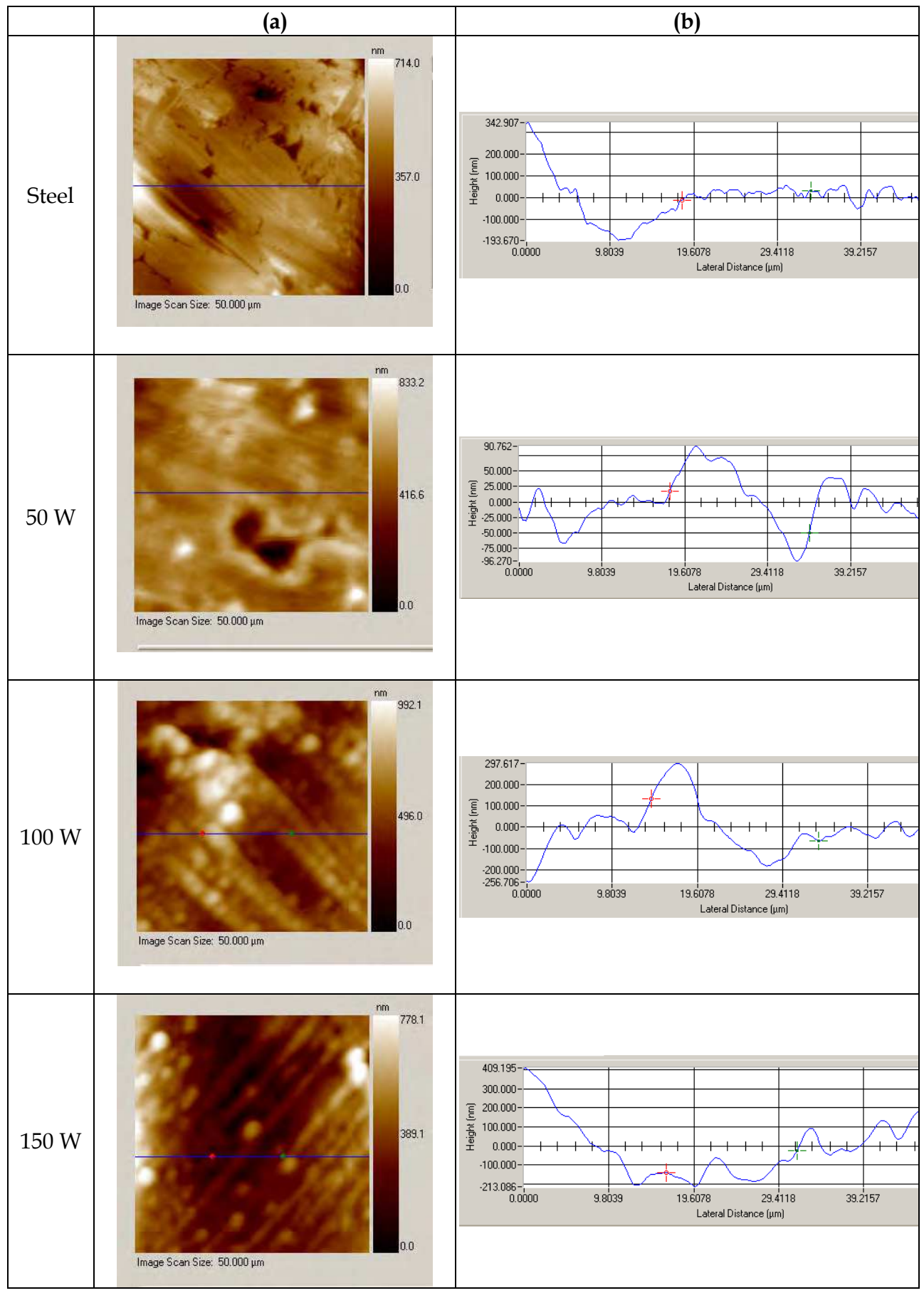




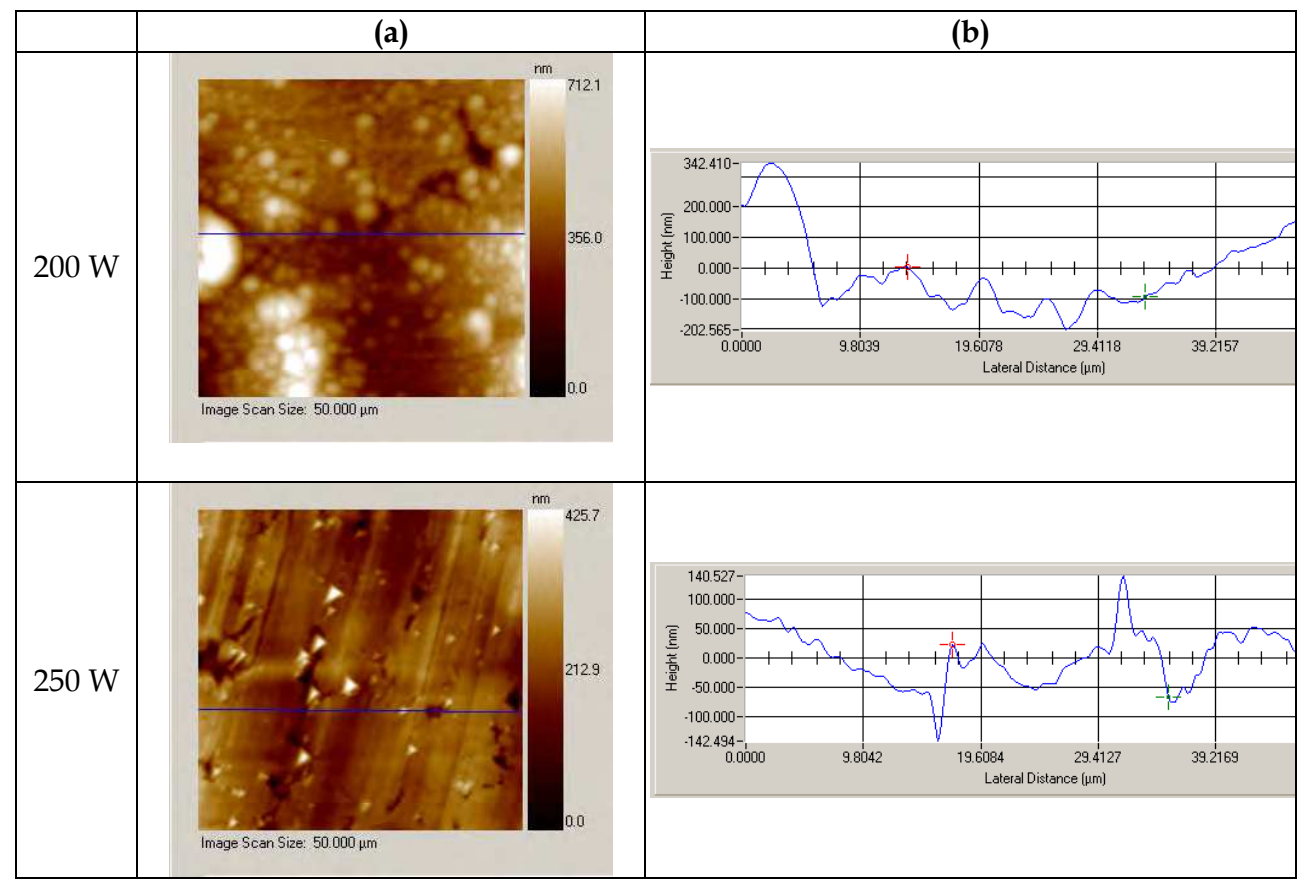

Fig. 17. (a) Surface topographical images of the carbon steel exposed to plasmas of different powers. The image of the non coated substrate is also presented. (b) Surface profiles taken in specific points of each sample, indicated by the blue line in the respective image.

Particles of different sizes are arranged in a string-like granular structure. As power is enhanced to $200 \mathrm{~W}$, the regularity of this pattern is lost and the compact organization of the particles suggests that there are connections amongst them. In this case, the stripes are detected only in the depressions and the defect evident in the image is a result of the incomplete covering of the substrate imperfections. Certainly, film is present in its bottom part, preventing early corrosion fail in this sample. The lack of organization may be a consequence of the higher fragmentation degree induced in the plasma phase with increasing P. Finally, the results obtained in the sample exposed to $250 \mathrm{~W}$ plasmas confirm that film was completely detached from the surface, remaining just small fragments connected to it.

Roughness was also evaluated from the $50 \times 50 \mu \mathrm{m}^{2}$ atomic force microscopy images and the results are plotted as a function of the plasma excitation power in Fig.18. The interval delineated by the dotted lines in the graph represents the range of roughness values for the bare substrate. Film deposition tended to increase the roughness of the carbon steel for any plasma excitation condition. Considering the scan length adopted in this case, the effect of the substrate imperfections on the RMS roughness is reduced as compared to the obtained in the results of Fig.8, determined by perfilometry. Even thought surface morphology is strongly affected by changing the plasma excitation power it has no evident influence on roughness which keeps roughly constant around $133 \mathrm{~nm}$. 


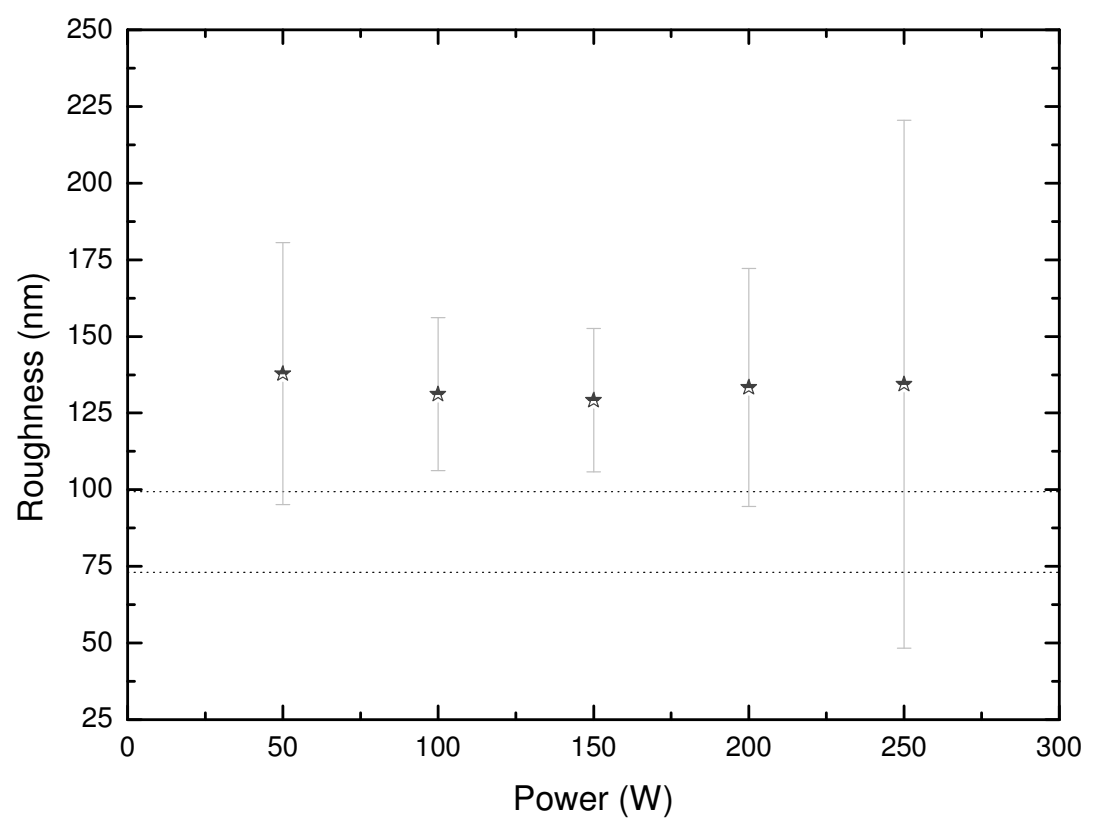

Fig. 18. Roughness of the films as a function of the plasma power. Results obtained from 50 $\mathrm{X} 50 \mu^{2}$ atomic force microscopy images. Region delimited by dotted lines represents the range of roughness for the bare carbon steel.

The behavior of the total resistance with roughness is presented in the graphs of Figs.19 (a) and (b). In Fig.19 (a) $R_{t}$ is plotted versus roughness derived from AFM images. No clear correlation is observed amongst the parameters in this picture. However, as $R_{t}$ is presented as a function of the roughness evaluated from the perfilometry profiles, Fig.19 (b), the results are separated into two groups: the first relative to the smoothest samples which presented high $R_{t}$ values and the other correspondent to the roughest samples which revealed low $R_{t}$ values. These results indicate that, besides thickness and silicon proportion, roughness also plays an important role on the performance of system in corrosive media. Therefore, if polished substrates were employed, still higher $R_{t}$ values would have been expected.

Therefore, the improvement by more than 6.000 times in the corrosion resistance of the carbon steel after the longest corrosion experiments is attributed to the association of high thickness values, moderate silicon contents and low roughness of the film prepared in 200 $\mathrm{W}$ plasmas. The integrity of this coating even after the corrosion test is another important aspect as one considers practical applications. 

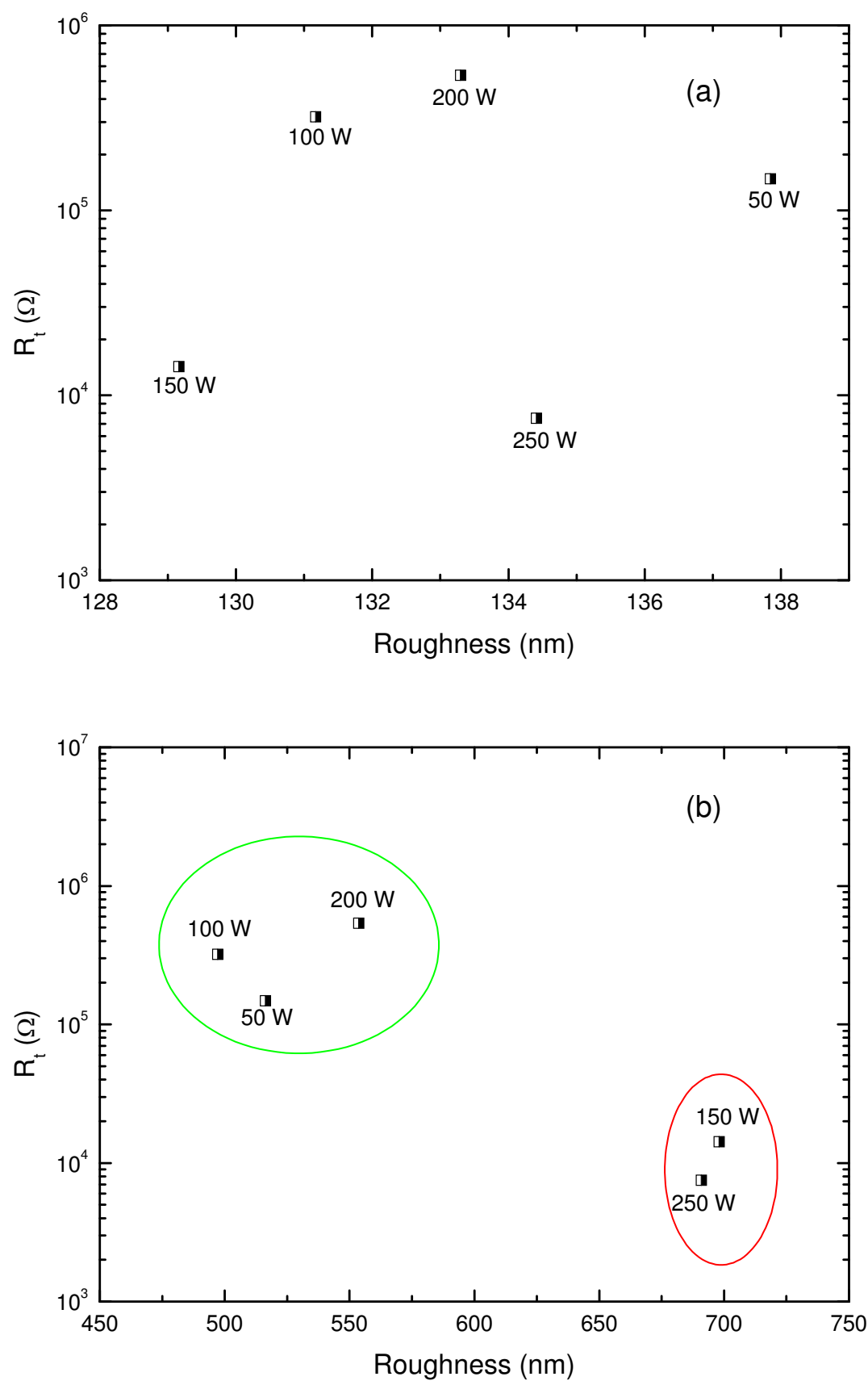

Fig. 19. Total resistance at $t=180$ minutes as a function of roughness determined from AFM images (a) and from perfilometry profiles (b). 


\section{Conclusions}

Molecular structure, chemical composition, morphology and topography of plasma deposited HMDSO films were strongly dependent on the plasma excitation power. The films are water repellent and present good adhesion to different substrates. Physical stability was a problem just for the layer prepared with the highest power in which thickness exceeded $10 \mu \mathrm{m}$, but the reduction in the deposition time would easily solve this drawback. All the other samples showed integrity even after aging in atmosphere conditions. The different reactivities of the hybrid organic-inorganic structure towards fluorine suggest it is a potential material for designing microelectromechanical devices. Moreover, films are transparent to visible light and highly resistant to oxygen attack, convenient properties as one considers the protection of a series of outdoor and space devices. In saline solutions, the most aggressive medium for steels, film deposition was observed to increase the corrosion resistance of the samples by more than 47.000 times. Differently of the results found in a previous work, the protection lasted until the end of the test, revealing an intact surface after the corrosion experiment. The optimum plasma treatment condition was considered to be the conducted with $200 \mathrm{~W}$ of power, since it provided the highest corrosion resistance for longer times. No intermediary oxide layer was grown in the metal surface and then all the improvements are ascribed to the HMDSO derived film. This opens the possibility of further improving the corrosion resistance of the carbon steel by creation of a dense oxide layer onto the metallic substrate prior to film deposition. New studies will be developed to evaluate this possibility. It should be finally mentioned that the films produced here are not exclusive to carbon steel protection since they adhere well to different substrates.

\section{Acknowledgment}

The authors would like to thank Brazilian agencies FAPESP and CNPq for financial support.

\section{References}

Biederman, H. e Osada, Y. 1992. Plasma Polymerization Processes. New York : Elsevier, 1992.

Bruce, R.L.; Lin, T.; Phaneuf, R.J.; Oehrleinb, G.S.; Bell, W.; Long, B.; Willson, C.G. 2010. Molecular structure effects on dry etching behavior of Si-containing resists in oxygen plasma. J. Vac. Sci. Technol. B. Jul 2010, Vol. 28, 4, pp. 751-757.

Chen, Q.; Zhang, D.; Tan, Z.; Wang, Z.; Liu, L.; Lu, J.Q. 2011. Thick benzocyclobutene etching using high density SF6/O2 plasmas. J. Vac. Sci. Technol. B. Jan 2011, Vol. 29, 1, pp. 011019-1 - 011019-6.

Choudhury, A.J.; Barve, S.A.; Chutia, J.; Pal, A.R.; Kishore, R.; Jagannath; Pande, M.; Patil, D.S. 2011. RF-PACVD of water repellent and protective HMDSO coatings on bell metal surfaces: Correlation between discharge parameters and film properties. Appl. Surf. Sci. Aug 2011, Vol. 257, pp. 8469-8477.

Choudhury, A.J.; Chutia, J.; Kakati, H.; Barve, S.A.; Pal, A.R.; Sarma, N.S.; Chowdhury, D.; Patil, D.S. Studies of radiofrequency plasma deposition of hexamethyldisiloxane films and their thermal stability and corrosion resistance behavior. Vacuum. Jun 2010, Vol. 84, 11. 
Fracassi, F.; d'Agostino, R.; Palumbo, F.; Angelini, E.; Grassini, S.; Rosalbino, F. 2003. Application of plasma deposited organosilicon thin films for the corrosion protection of metals. Surf. Coat. Technol. Sep 2003, Vols. 174-175, pp. 107-111.

Gengenbach, T.R. e Griesser, H.J. 1999. Polymer. Post-deposition ageing reactions differ markedly between plasma polymers deposited from siloxane and silazane monomers. Aug 1999, Vol. 40, 18, pp. 5079-5094.

Guruvenket, S.; Azzi, M.; Li, D.; Szpunar, J.A.; Martinu, L.; Klemberg-Sapieha, J.E. 2010. Structural, mechanical, tribological, and corrosion properties of a-SiC:H coatings prepared by PECVD. Surf. Coat. Technol. Aug 2010, Vol. 204, 21-22, pp. 3358-3365.

Huang, Y.; Tian, X.; Lv, S.; Yang, S.; Fu, R.K.Y.; Chu, P.K.; Leng, J.; Li, Y. 2011. An undercutting model of atomic oxygen for multilayer silica/alumina films fabricated by plasma immersion implantation and deposition on polyimide. Appl. Surf. Sci. Aug 2011, Vol. 57, 21, pp. 9158-9163.

Koch, G.H.; Brongers, M.P.H.; Thompson, N.G.; Virmani, Y. P.; Payer, J.H. 2002. Corrosion costs and preventive strategies in the United States. Nace International. 2002. available at http://events.nace.org/publicaffairs/images_cocorr/ccsupp.pdf.

Lanford, W.A.; Rand, M.J. 1978. The hydrogen content of plasma-deposited silicon nitride. J. App. Phys. Apr 1978, Vol. 49, 4, pp. 2473-2477.

Mansfeld, F. 1981. Recording and analysis of AC impedance data for corrosion studies: I. Background and methods of analysis. Corrosion. May 1981, Vol. 37, 5, pp. 301-307.

Morosoff, N. 1990. Plasma Deposition, Treatment and Etching of Polymers. [ed.] R. d'Agostino. New York: Academic Press, 1990.

Muntasser; Z.M.; Al-Darbi, M.M.; Islami, M.R., 2002. Corrosion. 2002.

Quéré, D. 2005. Non-sticking drops. Rep. Prog. Phys. 68, Nov 2005, pp. 2495-2532.

Radhakrishnan, S.; Sonawane, N.; Siju, C.R. 2009. Epoxy powder coatings containing polyaniline for enhanced corrosion protection. Progress in Organic Coatings. Mar 2009, Vol. 64, 4, pp. 383-386.

Rao, A.P.; Rao, A.V. 2010. Modifying the surface energy and hydrophobicity of the lowdensity silica aerogels through the use of combinations of surface-modification agents. Journal of Materials Science. Jan 2010, Vol. 41, 1, pp. 51-63.

Ricci, M.; Dorier, J.; Hollestein, C.; Fayet, P. 2011. Influence of Argon and Nitrogen Admixture in HMDSO/O2 Plasmas onto Powder Formation. Plasma Process. Polym. Feb 2011, Vol. 8, 2, pp. 108-117.

Scheinmann, F. 1970. An introduction to spectroscopic methods for the identification of organic compounds. Oxford : Pergamon Press, 1970. Vol. 1.

Shin, A.S.; Shon, M.Y. 2010. Effects of coating thickness and surface treatment on the corrosion protection of diglycidyl ether bisphenol-A based epoxy coated carbon steel. Journal of Industrial and Engineering Chemistry. 16, Nov 2010, Vol. 6, pp. 884890.

Stillahn, J.M., zhang, J., Fisherb, E.R. 2011. Surface interactions of SO2 and passivation chemistry during etching of $\mathrm{Si}$ and $\mathrm{SiO} 2$ in SF6/O2 plasmas. J. Vac. Sci. Technol. B. Jan 2011, Vol. 29, 1, pp. 011014-1 - 011014-10.

Tian, W.-C., Weigold, J.W., Pang, S.W. 2000. Comparison of Cl2 and F-based dry etching for high aspect ratio Si microstructures etched with an inductively coupled plasma source. J. Vac. Sci. Technol. B. Jul 2000, Vol. 18, 4, pp. 1890-1896. 
Ul, C.V.; Roux, F.; Laporte, C.B.; Pastol, J.L.; Chausse, A. 2002. Hexamethyldisiloxane (HMDSO)-plasma-polymerised coatings as primer for iron corrosion protection: influence of RF bias. J. Mater. Chem. Jun 2002, Vol. 12, 8, pp. 2318-2324.

Ul, C.V.; Laporte, C.B.; Benissad, N.; Chausse, A.; Leprince, P.; Messina, R. 2000. Plasmapolymerized coatings using HMDSO precursor for iron protection. Progress in Organic Coatings. Feb 2000, Vol. 38, 1, pp. 9-15.

Yasuda, H. 1985. Plasma Polymerization. New York : Academic Press, 1985. 


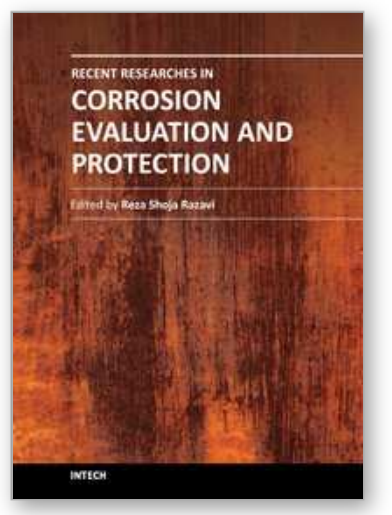

\section{Recent Researches in Corrosion Evaluation and Protection}

Edited by Prof. Reza Shoja Razavi

ISBN 978-953-307-920-2

Hard cover, 152 pages

Publisher InTech

Published online 25, January, 2012

Published in print edition January, 2012

The purpose of this book is to present and discuss the recent methods in corrosion evaluation and protection. The book contains six chapters. The aim of Chapter 1 is to demonstrate that Electrochemical Impedance Spectroscopy can be a very useful tool to provide a complete evaluation of the corrosion protection properties of electro-coatings. Chapter 2 presents results of studies of materials degradation from experimental electrochemical tests and theoretical calculations. Chapter 3 deals with the presentation of the corrosion and corrosion prevention of the aluminum alloys by organic coatings and inhibitors. Chapter 4 addresses the new method of pigment preparation that can improve protection efficiency. The effectiveness of plasma deposited films on the improvement of carbon steel corrosion resistance is discussed in Chapter 5. Chapter 6 deals with the conjugation of carbon nanotubes with organic-inorganic hybrid to prepare hybrid coatings that combine high anti-corrosion efficiency with elevated mechanical resistance.

\section{How to reference}

In order to correctly reference this scholarly work, feel free to copy and paste the following:

Rita C.C. Rangel, Tagliani C. Pompeu, José Luiz S. Barros Jr., César A. Antonio,Nazir M. Santos, Bianca O. Pelici, Célia M.A. Freire, Nilson C. Cruz and Elidiane C. Range (2012). Improvement of the Corrosion Resistance of Carbon Steel by Plasma Deposited Thin Films, Recent Researches in Corrosion Evaluation and Protection, Prof. Reza Shoja Razavi (Ed.), ISBN: 978-953-307-920-2, InTech, Available from: http://www.intechopen.com/books/recent-researches-in-corrosion-evaluation-and-protection/improvement-ofthe-corrosion-resistance-of-carbon-steel-by-plasma-deposited-thin-films

\section{INTECH}

open science | open minds

\section{InTech Europe}

University Campus STeP Ri

Slavka Krautzeka 83/A

51000 Rijeka, Croatia

Phone: +385 (51) 770447

Fax: +385 (51) 686166

www.intechopen.com

\section{InTech China}

Unit 405, Office Block, Hotel Equatorial Shanghai

No.65, Yan An Road (West), Shanghai, 200040, China 中国上海市延安西路65号上海国际贵都大饭店办公楼 405 单元

Phone: +86-21-62489820

Fax: $+86-21-62489821$ 
(C) 2012 The Author(s). Licensee IntechOpen. This is an open access article distributed under the terms of the Creative Commons Attribution 3.0 License, which permits unrestricted use, distribution, and reproduction in any medium, provided the original work is properly cited. 